\title{
Supporting Information for \\ Continuum model to define the chemistry and mass transfer in a bicarbonate electrolyzer
}

Eric W. Lees, ${ }^{1,2}$ Justin C. Bui, ${ }^{3,4}$ Datong Song, ${ }^{5}$ Adam Z. Weber, ${ }^{* 2,4}$ and Curtis P. Berlinguette*1,6,7,8

${ }^{1}$ Department of Chemical and Biological Engineering, The University of British Columbia, 2360 East Mall, Vancouver, British Columbia, V6T 1Z3, Canada.

${ }^{2}$ Energy Technologies Area, Lawrence Berkeley National Laboratory, Berkeley, CA 94720, USA.

${ }^{3}$ Department of Chemical and Biomolecular Engineering, University of California, Berkeley, Berkeley, CA 94720, USA

${ }^{4}$ Liquid Sunlight Alliance, Lawrence Berkeley National Laboratory, Berkeley, CA 94720, USA.

${ }^{5}$ Energy, Mining and Environment Research Centre, National Research Council Canada, Vancouver, B.C. V6T 1W5, Canada.

${ }^{6}$ Department of Chemistry, The University of British Columbia, 2036 Main Mall, Vancouver, British Columbia, V6T 1Z1, Canada.

${ }^{7}$ Stewart Blusson Quantum Matter Institute, The University of British Columbia, 2355 East Mall, Vancouver, British Columbia, V6T 1Z4, Canada.

${ }^{8}$ Canadian Institute for Advanced Research (CIFAR), 661 University Avenue, Toronto, M5G 1M1, Ontario, Canada.

${ }^{*}$ Corresponding authors: Adam Z. Weber (azweber@lbl.gov) and Curtis P. Berlinguette (cberling@.chem.ubc.ca) 


\section{Table of Contents}

1. Model development and theory $\quad 3$

1.1 Electrochemical reactions and charge transport 3

1.2 Water dissociation in the BPM 4

1.3 Donnan equilibrium at the BPM/cathode interface $\quad 5$

1.4 Transport of gas phase species $\quad 5$

1.5 Transport of liquid-phase species $\quad 9$

$\begin{array}{ll}1.6 \text { Boundary conditions } & 12\end{array}$

$\begin{array}{ll}1.7 \text { Numerical methods } & 14\end{array}$

1.8 Comparison to prior art 14

$\begin{array}{ll}1.9 \text { List of symbols } & 14\end{array}$

2. Materials and methods 19

2.1 Electrolyte preparation $\quad 19$

2.2 Membrane and electrode materials 19

2.3 Scanning electron microscopy 19

2.4 Electrolyzer design $\quad 20$

$\begin{array}{ll}2.5 \text { Electrolysis experiments } & 20\end{array}$

$\begin{array}{lr}\text { 3. Supplementary Tables and Figures } & 23\end{array}$

$\begin{array}{lr}\text { 4. References } & 37\end{array}$ 


\section{Model development and theory}

\subsection{Electrochemical reactions and charge transport}

$\mathrm{CO}_{2}$ electrolysers produce $\mathrm{CO}$ and $\mathrm{H}_{2}$ with a cumulative $F E$ of $\sim 100 \%$ under near-neutral conditions when using a silver electrocatalyst. ${ }^{1,2}$ The rate of these multi-electron processes, in terms of partial current densities for $\mathrm{CO}_{2}$ reduction $\left(i_{C O 2 R R}\right)$ and hydrogen evolution $\left(i_{H E R}\right)$, are given by Butler-Volmer expressions which depend on reactant concentrations at the silver/electrolyte interface, ${ }^{3}$

$$
\begin{gathered}
i_{C O 2 R R}=-i_{0, C O 2 R R}\left(\frac{c_{C O_{2}(a q)}}{1 M}\right)^{1.5} \exp \left(-\frac{\alpha_{c, C O 2 R R} F}{R T} \eta_{C O 2 R R}\right) \\
i_{H E R, \text { base }}=-i_{0, H E R}^{B} \exp \left(-\frac{\alpha_{c, H E R}^{B}}{R T} \eta_{H E R}\right) \\
i_{H E R, \text { acid }}=-i_{0, H E R}^{A}\left(\frac{c_{H^{+}}}{1 M}\right) \exp \left(-\frac{\alpha_{c, H E R}^{A} F}{R T} \eta_{H E R}\right)
\end{gathered}
$$

Eq. S1

Where $i_{0, C O 2 R R}, i_{0, H E R^{\prime}}^{B}$ and $i_{0, H E R}^{A}$ are the exchange current densities for $\mathrm{CO}_{2}$ reduction, hydrogen evolution in basic conditions, and hydrogen evolution in acidic conditions, respectively. These values along with the corresponding transfer coefficients $\left(\alpha_{c, C O 2 R R}, \alpha_{c, H E R}^{B}\right.$, and $\left.\alpha_{c, H E R}^{A}\right)$ were obtained from past works. ${ }^{3,4}$ Each electrochemical reaction $k$ has an associated surface overpotential $\left(\eta_{\mathrm{k}}\right)$ corresponding to the difference between the applied potential and the thermodynamic equilibrium potential (which is corrected for non-standard $\mathrm{pH}$ values by a Nernstian shift),

$$
\eta_{k}=\phi_{s}-\phi_{l}-\left(U_{k}^{0}-\frac{2.303 R T}{F} p H\right)
$$

Eq. $\mathbf{S 4}$

Where $U_{k}^{0}$ is the standard reduction potential of reaction $k, R$ is the universal gas constant $\left(8.314 \mathrm{~J} \mathrm{~mol}^{-1}\right.$ $\left.\mathrm{K}^{-1}\right), F$ is Faraday's constant $\left(94685 \mathrm{C} \mathrm{mol}^{-1}\right)$ and $T$ is the temperature $(298.15 \mathrm{~K})$. The bulk solid phase 
current density $\left(i_{s}\right)$ is related to the liquid phase current density by electroneutrality, and Ohm's law in tandem with the Bruggeman equation (which accounts for porosity and tortuosity) is used to determine the solid phase potential $\left(\phi_{s}\right)$.

\subsection{Water dissociation in the BPM}

Water dissociation in BPMs is driven by an electric field which shift the equilibrium towards $\mathrm{H}^{+}$ and $\mathrm{OH}^{-}$at the AEL/CEL interface. ${ }^{5,6}$ Heterogeneous catalysts with basic or acidic groups on the surface (e.g., graphene $\mathrm{g}^{7-9}$ and metal oxides ${ }^{10,11}$ ) are commonly used to accelerate water dissociation at this interface. These complex phenomena are the focus of other works ${ }^{12,13}$ and were not modeled explicitly here. Rather, the flux of $\mathrm{H}^{+}$at the AEL/CEL interface was assumed to constitute $90 \%$ of the total ionic current, with $\mathrm{K}^{+}$transport accounting for the balance of change transport. This value is based on experimental and computational studies which demonstrate high water dissociation rates and low ion crossover in BPMs when operating at current densities $>30 \mathrm{~mA} \mathrm{~cm}{ }^{-2}{ }^{13,14}$ We therefore defined the transference numbers of $\mathrm{H}^{+}$and $\mathrm{K}^{+}$at the AEL/CEL interface to be equal to 0.9 and 0.1 , respectively, for the base case simulation. The corresponding boundary conditions for the fluxes of $\mathrm{H}^{+}\left(\left.n_{\mathrm{H}+}\right|_{x=0}\right)$ and $\mathrm{K}^{+}$ $\left(\left.n_{\mathrm{K}+}\right|_{x=0}\right)$ were defined using Faraday's Law of Electrolysis,

$$
\begin{gathered}
\left.n_{\mathrm{H}+}\right|_{x=0}=t_{\mathrm{H}+\frac{1}{n_{W D} F}} \int_{\substack{x=L_{C E L} \\
x=L_{C E L}+L}} i_{\text {total }} d x \\
n_{\mathrm{K}+\left.\right|_{x=0}}=t_{K^{+}} \frac{1}{n_{W D} F} \int_{x=L_{C E L}} i_{\text {total }} d x
\end{gathered}
$$

Where $\mathrm{n}_{\mathrm{WD}}$ represents the number of electrons consumed per mole of $\mathrm{H}^{+}$produced. This model formulation allows one to simulate the acid-base reactions that occur within the membrane without 
needing to model water dissociation at the AEL/CEL interface explicitly (which would be computationally expensive and engender numerical convergence issues). ${ }^{12,13}$

\subsection{Donnan equilibrium at the BPM/cathode interface}

The $x=L_{C E L}$ position represents the interface between the BPM and the liquid electrolyte in the CL. At this boundary, negative charges in the CEL repel cations and attract anions that are present in the electrolyte phase. In order to determine partitioning of mobile ions across this boundary, we assumed that the chemical potentials of each species on either side were equal. Therefore, the system can be described by Donnan equilibrium,

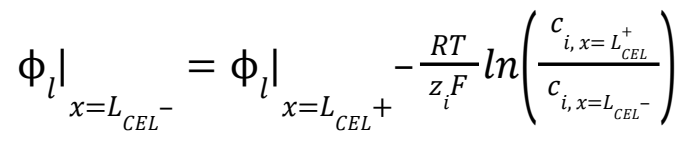

Where $c_{i, x=L_{C E L}^{+}}$and $c_{i, x=L_{C E L}^{-}}$are the concentrations of species $i$ on the electrolyte and membrane sides, respectively, of the CEL/CL interface. The electrolyte current density $\left(i_{l}\right)$ and molar fluxes $\left(n_{l}\right)$ are continuous at the CEL/CL interface; however, the electrolyte potential $\left(\phi_{l}\right)$ is discontinuous due to the fixed charges in the membrane.

\subsection{Transport of gas phase species}

Gas transport must be accounted for in the $\mathrm{CL}$ due to the formation of $\mathrm{CO}, \mathrm{H}_{2}$, and $\mathrm{CO}_{2}$ bubbles during electrolysis. However, the volume fraction and distribution of these gases in the CL is challenging to quantify operando CL given the multiphase flow and bubble formation phenomena. ${ }^{15,16}$ Therefore, we assumed a liquid saturation of $80 \%$ for simplicity and modeled the silver foam CL as a porous electrode with solid conductor, liquid electrolyte, and gas phases of volume fraction $\left(1-\varepsilon_{C L}\right)$, 
$s_{C L} \varepsilon_{C L}$, and $\left(1-s_{C L}\right) \varepsilon_{C L}$, respectively. The governing mass conservation equations for each gaseous species $j\left(j=\mathrm{CO}_{2}, \mathrm{CO}, \mathrm{H}_{2}\right.$, and $\left.\mathrm{N}_{2}\right)$ are given as,

$$
\begin{gathered}
\nabla \cdot n_{C O_{2}}=-R_{P T, C O_{2}} \\
\nabla \cdot n_{H_{2}}=R_{C T, H_{2}} \\
\nabla \cdot n_{C O}=R_{C T, C O} \\
\nabla \cdot n_{N 2}=0
\end{gathered}
$$

Eq. $\mathbf{S 8}$

Eq. S9

Eq. S10

Eq. S11

where the phase transfer of $\mathrm{CO}_{2}$ from the gas to liquid phase $\left(R_{P T, C O}\right)$ is a key parameter that directly affects the rate of $\mathrm{CO}_{2}$ reduction. ${ }^{17}$ One can estimate this parameter using a mass transfer correlation approach that incorporates Henry's Law, ${ }^{4}$

$$
R_{P T, C O}=a_{v} k_{G L, C O} M_{C O_{2}}\left(H_{C O_{2}} p_{g} y_{C_{2}}{ }^{-C_{C O}(a q)}\right)
$$

According to this equation, $\mathrm{CO}_{2}$ dissolves from the gas phase into the liquid phase for $R_{P T, C O_{2}}>0$ and $\mathrm{CO}_{2}$ is liberated from the solution for $R_{P T, C O}<0$. The active surface area of the CL was estimated to be $40,000 \mathrm{~m}^{-1}$ based on previous studies of metallic foams. ${ }^{18} \mathrm{CO}_{2}$ diffusion rates from the bulk to the surface were estimated using a mass transfer coefficient for $\mathrm{CO}_{2}$,

$$
k_{G L, C O_{2}}=\frac{D_{C O_{2}(a q)}}{\delta_{T F}}
$$


where $D_{\mathrm{CO}_{2}(a q)}$ is the diffusion coefficient of $\mathrm{CO}_{2}$ in the liquid electrolyte and $\delta_{T F}$ is the thickness of the thin film of electrolyte covering the pore walls in the CL, which was estimated from the pore radius and liquid saturation as, ${ }^{4}$

$$
\delta_{T F}=r_{C L}\left(1-\sqrt{1-S_{C L}}\right)
$$

Electrochemically-generated $\mathrm{CO}$ and $\mathrm{H}_{2}$ were assumed to have negligible solubility in the electrolyte and therefore exist only in the gas phase. ${ }^{19}$ The associated charge transfer source terms $\left(R_{C T, j}\right)$ for gas species $j=\mathrm{CO}$ and $j=\mathrm{H}_{2}$ were determined as,

$$
R_{C T, j}=-M_{j, k} \frac{a_{v} s_{j, k} i_{k}}{n_{k} F}
$$

where $s_{j, k}$ is the stoichiometric coefficient of species $j$ in reaction $k$ (i.e., $\mathrm{CO}_{2}$ reduction or hydrogen evolution), $n_{k}$ is the number of electrons transferred, and $i_{k}$ is the partial current density for reaction $k$.

The net mass flux of each gaseous species $j$ was determined by accounting for diffusive and convective mass transfer,

$$
n_{j}=-\rho_{g} D_{j}^{e f f} \nabla \omega_{j}-\rho_{g} D_{j}^{e f f} \omega_{j} \frac{\nabla M_{n}}{M_{n}}+\rho_{j} u_{g}
$$

Where $\omega_{j}$ is the mass fraction of species $j, \rho_{g}$ is the mass density of the gaseous mixture (determined by the ideal gas law), and $\rho_{j}$ is the mass density of an individual species $j . D_{j}^{e f f}$ is the effective diffusion coefficient of species $j, M_{j}$ is the molar mass of gaseous species $j, M_{n}$ is the average molar mass of the gaseous mixture, and $u_{g}$ is the velocity of the gaseous mixture in the CL. The diffusion coefficient of 
species $j, D_{j}$, was determined by considering molecular diffusion (i.e., the mass-averaged

Stefan-Maxwell diffusion coefficient, $D_{j}^{m}$ ) and the mass transfer resistance due to interactions between the chemical species and the porous medium (i.e., the Knudsen diffusion coefficient, $D_{j}^{K}$ ):

$$
\begin{gathered}
D_{j}=\left(\frac{1}{D_{j}^{m}}+\frac{1}{D_{j}^{K}}\right)^{-1} \\
D_{j}^{m}=\frac{1-\omega_{j}}{\sum_{i}^{\frac{y_{j}}{D_{j, o}}}} \\
D_{j}^{K}=\frac{2 r_{C L}}{3} \sqrt{\frac{8 R T}{\pi M_{j}}}
\end{gathered}
$$

where $y_{j}$ is the molar fraction of gaseous species $j, D_{j, o}$ is the binary diffusivity of species $j$ and $o$, and $r_{C L}$ is the average pore radius in the CL. The density of the gaseous mixture, $\rho_{g}$, was estimated using the ideal gas law for an ideal mixture. To account for mass-transfer resistances within the porous CL, the effective diffusion coefficient of species $j, D_{j}^{e f f}$, was estimated using the Bruggeman equation as above.

The velocity profile and convective terms in the mass-conservation equations were then determined using Darcy's Law and the Carman-Kozeny equation to account for flow in porous media,

$$
u_{g}=-\frac{\kappa_{s a t, C L} \kappa_{r g, C L}}{\mu_{g, C L}} \frac{\left(\varepsilon_{C L}\right)^{3}}{\left(1-\varepsilon_{C L}\right)^{2}} \nabla p_{g}
$$

where $\mu_{g, C L}$ is the gas viscosity and $\kappa_{s a t, C L}^{0}$ is the bulk saturated permeability (which was estimated based on Zenyuk et $\left.a .^{20}\right)$. The relative permeability of the CL $\left(\kappa_{r g, C L}\right)$ can be then computed based on the water saturation as follows, ${ }^{21}$

$$
\kappa_{r g, C L}=\left(1-S_{C L}\right)^{3}
$$




\subsection{Transport of liquid-phase species}

Dilute-solution theory was used to model the transport of chemical species in the liquid phase. This theory assumes that the activity coefficients are equal to unity, and that the diffusion rate of each chemical species is independent of the other species present in solution. Concentrated-solution theory is a more accurate approach, but it would also require the use of various binary interaction parameters, many of which are unknown, and therefore would greatly increase the numerical complexity of the model. Moreover, the concentrations investigated in this study can be considered dilute without introducing considerable error. ${ }^{3,4}$ The governing mass balances for each liquid species $i\left(i=\mathrm{CO}_{2(\mathrm{aq})}, \mathrm{K}^{+}\right.$, $\mathrm{H}^{+}, \mathrm{OH}^{-}, \mathrm{HCO}_{3}^{-}$, and $\mathrm{CO}_{3}{ }^{2-}$ ) are given as,

$$
\begin{gathered}
\nabla \cdot n_{\mathrm{CO}_{2}(\mathrm{l})}=R_{\mathrm{CT}_{\mathrm{COO}}}+R_{\mathrm{B}, \mathrm{CO} \mathrm{O}_{2}}+R_{\mathrm{PT}, \mathrm{CO}{ }_{2}} \\
\nabla \cdot n_{\mathrm{K}^{+}}=0 \\
\nabla \cdot n_{\mathrm{H}^{+}}=R_{\mathrm{CT}, \mathrm{H}^{+}}+R_{\mathrm{B}, \mathrm{H}^{+}} \\
\nabla \cdot n_{\mathrm{OH}^{-}}=R_{\mathrm{CT}, \mathrm{OH}^{-}}+R_{\mathrm{B}, \mathrm{OH}}^{-} \\
\nabla \cdot n_{\mathrm{HCO}_{3}^{-}}=R_{B, \mathrm{HCO}_{3}^{-}} \\
\nabla \cdot n_{\mathrm{CO}_{3}^{2-}}=R_{B, \mathrm{CO}_{3}^{2-}}
\end{gathered}
$$

Eq. S22

Eq. $\mathbf{S 2 3}$

Eq. S24

Eq. $\mathbf{S 2 5}$

Eq. S26

Eq. $\mathbf{S 2 7}$

where $R_{\mathrm{CT}_{\mathrm{CO}}}, R_{\mathrm{CT}, \mathrm{H}^{+}}$, and $R_{\mathrm{CT}, \mathrm{OH}^{-}}$are calculated using Eq. S15 to account for species consumption and generation by $\mathrm{CO}_{2}$ reduction (Eq. 5) and hydrogen evolution (Eq. 6). Homogeneous reactions, which include the (bi)carbonate equilibrium (Eqs. 3, 4 and 7, 8), and water dissociation reactions (Eq. 1), occur within the CEL and CL. These reversible, acid-base reactions are responsible for converting bicarbonate into $\mathrm{CO}_{2}$ in situ. We did not assume that these reactions necessarily reach equilibrium ${ }^{22}$ 
because of the complex $\mathrm{pH}$ gradients previously observed in $\mathrm{CO}_{2}$ and bicarbonate electrolyzers. ${ }^{23}$ Therefore, the reactions were treated as a system of kinetics expressions as follows,

$$
R_{B, i}=M_{i} \sum_{n} s_{i, n}\left(k_{n} \prod_{s_{i, n}<0} c_{i}^{-s_{i, n}}-\frac{k_{n}}{K_{n}} \prod_{s_{i, n}>0} c_{i}^{s_{i, n}}\right)
$$

where $s_{i, n}$ is the stoichiometric coefficient of species $i$ in homogeneous bulk reaction $n\left(s_{i, n}<0\right.$ for reactants and $s_{i, n}>0$ for products), $K_{n}$ is the equilibrium constant of homogeneous reaction $n$, and $k_{n}$ and $k_{-n}$ are the forward and reverse reaction rate constants for reaction $n$, respectively. With these source terms from reactions, the net flux of each liquid species, $n_{i}$, can be determined using the Nernst-Planck with effective diffusion coefficients as above:

$$
n_{i}=-D_{i}^{e f f} \nabla c_{i}+z_{i} \frac{F}{R T} D_{i}^{e f f} c_{i} \nabla \phi_{l}+c_{i} u_{l}
$$

To reduce model complexity, the electroneutrality condition was imposed instead of the Poisson equation to simultaneously solve for the potential, current, and concentration profiles,

$$
\sum_{i} z_{i} c_{i}=0
$$

The CEL membrane has fixed negative charges (e.g., $-\mathrm{SO}_{3}^{-}$groups) which also contribute to the electroneutrality equation above. Membrane properties for the CEL, including the ion exchange capacity $(I E C)$ and membrane density $\left(\rho_{M}\right)$, were obtained from literature. ${ }^{13,24}$

Because the CL is porous, effective diffusion coefficients for the liquid phase species $\left(D_{i}^{e f f}\right)$ must account for mass transfer resistances associated with porosity and tortuosity. The Bruggeman 
equation provides a simple estimation of these effects on the nominal diffusion coefficients in aqueous media $\left(D_{i, w}\right)$,

$$
D_{i}^{e f f}=\left(\varepsilon_{C L} S_{C L}\right)^{3 / 2} D_{i, w}
$$

In the CEL, the porosity was correlated to membrane hydration $(\lambda)$ : the molar ratio of water to fixed-charge groups in the membrane phase. Consequently, effective diffusion coefficients were determined based on the water volume fraction of the membrane phase $(\boldsymbol{\Phi})$ and a tortuosity parameter $(q$ ) that was assigned a value of 1 as per Vermaas et al. ${ }^{25}$ The equations are given by Grew et al., ${ }^{26}$

$$
\begin{gathered}
D_{i}^{e f f}=\frac{\boldsymbol{\Phi}^{q} D_{i, w}}{x_{w}} \\
\boldsymbol{\Phi}=\frac{\lambda V_{W}}{\lambda V_{W}+V_{M}} \\
x_{w}=\frac{\lambda}{\lambda+1}
\end{gathered}
$$

Where $V_{W}$ and $V_{M}$ are the molar volumes of water and the membrane phase, respectively. $\mathrm{x}_{\mathrm{w}}$ is the mole fraction of water in the CEL. In order to determine the water saturation, one must consider that membranes saturated with alkali cations have lower water saturations than those saturated with $\mathrm{H}^{+}$. However, there is generally a lack of available data on membrane hydration values under electrolysis conditions. We therefore assumed that membrane hydration varied linearly with the molar ratio of protons to fixed-charge groups in the membrane $\left(x_{H^{+}}\right)$as per Bui et al., ${ }^{13}$

$$
\lambda=\lambda_{x_{H^{+}}=0}+x_{H^{+}} \lambda_{x_{H^{+}}=1}
$$


where $\lambda_{x_{H^{+}}=0}=6$ and $\lambda_{x_{H^{+}}=1}=9$ are hydration values (i.e., the molar ratio of water to sulfonate groups in the membrane) fit to experimental BPM data collected for a salt solution and deionized water, respectively. ${ }^{13}$

Darcy's law was used to determine the mass-averaged velocity in the liquid phase based on the effective permeability of the liquid phase $\left(\kappa_{l}^{e f f}\right)$,

$$
u_{l}=-\frac{\kappa_{l, c a}^{e f f}}{\mu_{l}} \nabla p_{l}
$$

where $\mu_{l}$ and $p_{l}$ are the viscosity and pressure of the liquid phase, respectively. $\kappa_{l}^{e f f}$ was estimated as,

$$
\kappa_{l}^{e f f}=\kappa_{s a t, C L} \kappa_{r l, C L}
$$

where $\kappa_{r l}$ is the relative permeability of the liquid phase, ${ }^{27}$

$$
\kappa_{r l, C L}=s_{C L}^{3}
$$

\subsection{Boundary conditions}

As shown in Fig. 1b, the electrolyte potential at the AEL/CEL interface $(x=0)$ is set to an arbitrary reference value of $0 \mathrm{~V}$ vs. the reversible hydrogen electrode. As a proxy for modeling water dissociation at the AEL/CEL interface, Eq. S5 and Eq. S6 are imposed as boundary conditions for the fluxes of $\mathrm{H}^{+}$and $\mathrm{K}^{+}$, respectively. Different rates of water dissociation are simulated by modulating $t_{\mathrm{H}+}$ and $t_{\mathrm{K}+}$ in these equations. No flux (Dirichlet) boundary conditions are used for the other liquid phase species at this interface. 
Transport of mass and charge in the gas and solid phases is only modeled in the CL. Consequently, Direchlet boundary conditions are imposed on all state variables related to gas phase mass and momentum conservation equations at the $\mathrm{CEL} / \mathrm{CL}$ interface. Moreover, the solid phase current density is set equal to the liquid phase current density at this interface to obey electroneutrality.

At the $\mathrm{CL} /$ flow plate interface, the following mass transfer correlation is used to determine the mass flux of gas and liquid species into the electrode,

$$
\left.n_{i}\right|_{x=L_{C L}+L_{C E L}}=k_{M T, i}\left(c_{i}^{0}-c_{i, x=L_{C L}+L_{C E L}}\right)
$$

Where $c_{i}^{0}$ represents the bulk concentration of gas and liquid in the flow channel (see Table $\mathbf{1}$ for the bulk concentrations used in the basecase model). The convective mass-transfer coefficient $k_{M T, i}$ of each species $i$ in the gas and liquid phases were estimated based on a semi-empirical correlation, ${ }^{4}$

$$
k_{M T, i}=0.664 \frac{D_{j}}{L_{\text {electrode }}} \operatorname{Re}_{i}^{1 / 3} \mathrm{Sh}_{i}^{1 / 2}
$$

where $\mathrm{Re}_{i}$ and $\mathrm{Sh}_{i}$ are the Reynolds and Schmidt numbers, respectively, for species $i$ in the gas and liquid phases. These dimensionless groups are defined based on a characteristic length of $L_{\text {electrode }}$. Corresponding linear velocities in the flow plate were assigned as Dirichlet boundary conditions at the $\mathrm{CL} /$ flowplate interface. The liquid phase current density was set to 0 and the solid phase potential was modulated from -1.5 to $-2.1 \mathrm{~V}$ in $0.05 \mathrm{~V}$ increments to simulate a range of current densities. 


\subsection{Numerical methods}

The system of partial differential equations was solved using the MUMPS (MUltifrontal Massively Parallel sparse direct Solver) in COMSOL Version 5.5. The model domain has a maximum element size of $0.01 \mu \mathrm{m}$ and a relative tolerance of 0.001 .

\subsection{Comparison to prior art}

While the model presented here builds upon prior work, ${ }^{3,4}$ it also presents new physics heretofore unexplored in prior $\mathrm{CO}_{2}$ reduction models. First, because $\mathrm{CO}_{2}$ reduced in the model is generated in situ in the CEL, as opposed to being directly fed at the flow plate, the boundary conditions in the model differ from those in prior studies. Specifically, the water dissociation proton flux boundary condition at the AEL/CEL interface presents an advance relative to prior studies, as there exists no macro-homogeneous continuum model for a bipolar membrane $\mathrm{CO}_{2}$ reduction electrolyzer which uses protons to liberate $\mathrm{CO}_{2}$ from a bicarbonate solution. Moreover, our model explicitly calculates the ideal Donnan equilibrium at the CEL/CL interface to determine the partitioning of bicarbonates into the CEL. This model feature is required to describe in situ $\mathrm{CO}_{2}$ generation, which has not been previously captured in models of $\mathrm{CO}_{2}$ reduction.

\subsection{List of symbols}

\begin{tabular}{ll} 
Roman & \\
\hline$a_{v}$ & Specific surface area, $\mathrm{m}^{-1}$ \\
$c_{i}$ & Concentration of species $i, \mathrm{M}$ \\
$D_{i}$ & Diffusion coefficient of species $i, \mathrm{~m}^{2} \mathrm{~s}^{-1}$ \\
$F$ & Faraday's constant, $\mathrm{C} \mathrm{mol}^{-1}$
\end{tabular}




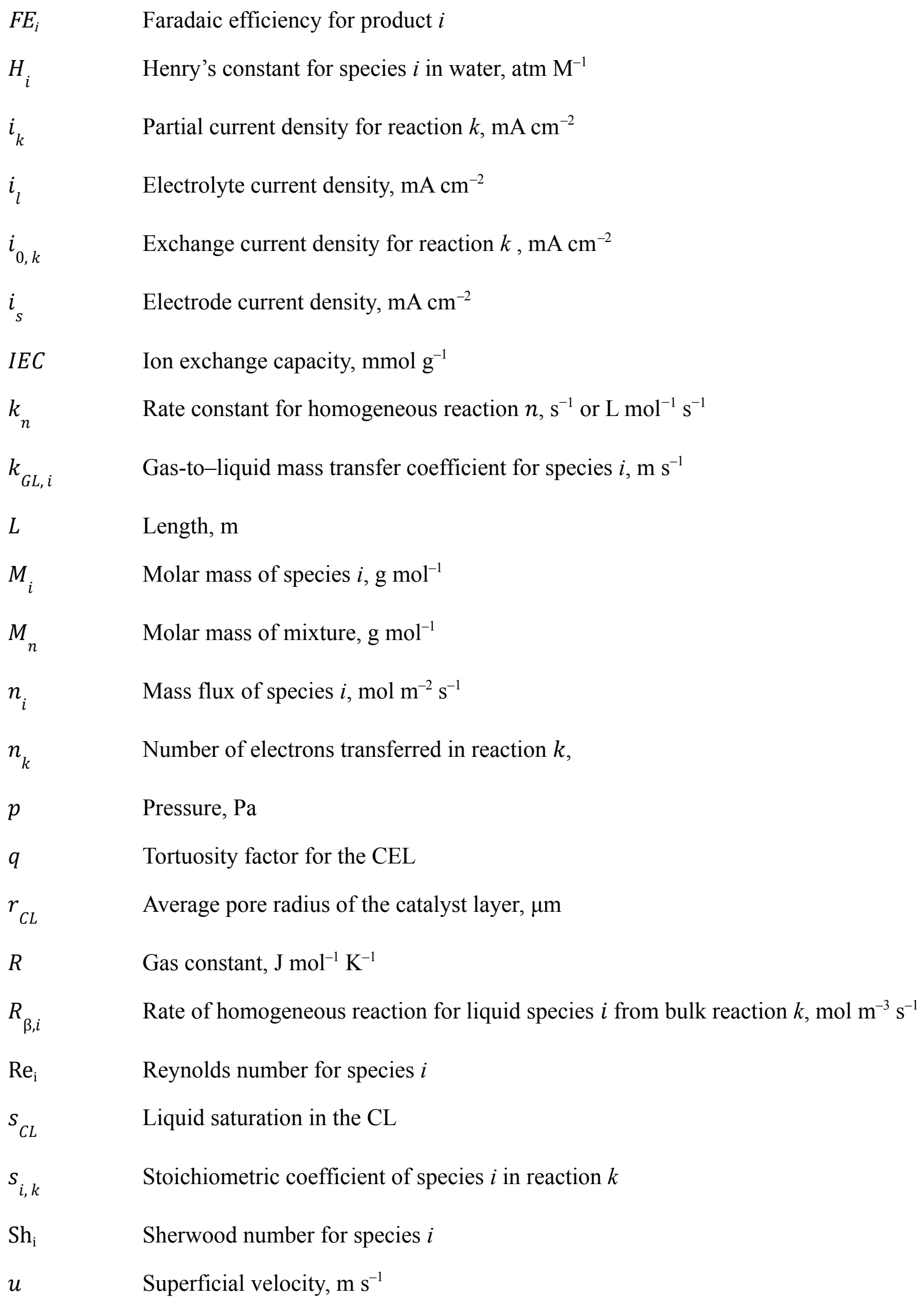




\begin{tabular}{|c|c|}
\hline$T$ & Temperature, $\mathrm{K}$ \\
\hline$U_{k}$ & Half-cell potential of reaction $k, \mathrm{~V}$ \\
\hline$x_{H^{+}}$ & Molar ratio of $\mathrm{H}^{+}$to fixed-charge groups in the CEL \\
\hline$x_{w}$ & Molar ratio of water to the sum of the water and fixed charge species in the membrane \\
\hline$y_{i}$ & Mole fraction of species $i$ \\
\hline$z_{i}$ & Electron valency of species $i$ \\
\hline \multicolumn{2}{|l|}{ Greek } \\
\hline$\alpha_{k}$ & Charge-transfer coefficient for reaction $k$ \\
\hline$\delta_{T F}$ & Thickness of electrolyte boundary layer, $\mathrm{m}$ \\
\hline$\varepsilon_{C L}$ & Porosity of the CL \\
\hline$\eta_{k}$ & Overpotential of reaction $k, \mathrm{~V}$ \\
\hline$\kappa_{C L}$ & Permeability of the $\mathrm{CL}, \mathrm{m}^{2}$ \\
\hline$\lambda$ & Membrane hydration, mol $\mathrm{H}_{2} \mathrm{O}$ per mol of $\mathrm{SO}_{3}^{-}$ \\
\hline$\mu_{\alpha}$ & Viscosity of phase $\alpha$, Pa s \\
\hline$\mu_{i}$ & Viscosity of pure species $i, \mathrm{~Pa} \mathrm{~s}$ \\
\hline$\rho_{\mathrm{a}}$ & Density of phase $\mathrm{a}, \mathrm{g} \mathrm{cm}^{-3}$ \\
\hline$\rho_{i}$ & Mass concentration of pure species $i, \mathrm{~g} \mathrm{~cm}^{-3}$ \\
\hline$\sigma_{C L}$ & Conductivity of the $\mathrm{CL}, \mathrm{S} \mathrm{m}^{-1}$ \\
\hline$\phi_{s}$ & Solid-phase potential, $\mathrm{V}$ \\
\hline$\phi_{l}$ & Liquid-phase potential, $\mathrm{V}$ \\
\hline$\Phi$ & Water volume fraction of the ionomer phase \\
\hline$\omega_{j}$ & Mass fraction of gaseous species $j$ \\
\hline Subscript & \\
\hline
\end{tabular}




\begin{tabular}{|c|c|}
\hline acid & Acidic conditions \\
\hline$a q$ & Aqueous \\
\hline basic & Basic conditions \\
\hline$C L$ & Catalyst layer \\
\hline$C T$ & Charge transfer \\
\hline fixed & Fixed charge groups \\
\hline$i$ & Liquid phase chemical species \\
\hline$j$ & Gas phase chemical species \\
\hline$g$ & Gas \\
\hline$l$ & Liquid \\
\hline$M T$ & Mass transfer \\
\hline outlet & Outlet of the electrolyzer \\
\hline$P T$ & Phase transfer \\
\hline$r l$ & Relative to the liquid phase \\
\hline$r g$ & Relative to the gas phase \\
\hline$T F$ & Thin film \\
\hline$w$ & Water \\
\hline \multicolumn{2}{|l|}{ Superscript } \\
\hline$A$ & Acidic conditions \\
\hline$B$ & Basic conditions \\
\hline eff & Effective \\
\hline$K$ & Knudsen \\
\hline$m$ & Mass-averaged \\
\hline 0 & Standard state \\
\hline ref & Reference state \\
\hline Acronyms & \\
\hline
\end{tabular}

BPM Bipolar membrane 
CL Catalyst layer

CEL Cation exchange layer

AEL Anion exchange layer

CO2RR $\quad \mathrm{CO}_{2}$ reduction reaction

HER Hydrogen evolution reaction 


\section{Materials and methods}

\subsection{Electrolyte preparation}

Bicarbonate solutions were prepared by adding $150 \mathrm{~g}$ of $\mathrm{KHCO}_{3}(99.5 \%$, Alfa Aesar, USA) and $2.9 \mathrm{~g}$ of ethylenediaminetetraacetic acid (EDTA; 99\%, Sigma Aldrich, USA) to $500 \mathrm{~mL}$ of deionized water $\left(18.2 \mathrm{M} \Omega \cdot \mathrm{cm} ; 25^{\circ} \mathrm{C}\right)$. The EDTA was added to chelate metal ion impurities that can deposit on the catalyst surface. ${ }^{28}$ The $\mathrm{pH}$ was measured using a AE150 $\mathrm{pH}$ benchtop meter purchased from Fisher Scientific (USA) after the bicarbonate salt and EDTA was stirred and dissolved in the solution.

\subsection{Membrane and electrode materials}

Fumasep FBM bipolar membranes were purchased from Fuel Cell Store (USA) and stored in 1 $\mathrm{M} \mathrm{NaCl}$. Nickel foams (>99.99\%) were purchased from MTI Corporation (USA) and compressed to 50 kN using a hydraulic press. Silver foams were purchased from Jiangsu Green Materials Hi-Tech. Co. Ltd. (China). Concentrated nitric acid (70 wt \%) was purchased from Fisher Scientific (USA) and mixed with deionized water $\left(18.2 \mathrm{M} \Omega \cdot \mathrm{cm} ; 25{ }^{\circ} \mathrm{C}\right)$ at a $7: 3$ volume ratio to prepare a $30 \%(\mathrm{v} / \mathrm{v})$ etching solution. Cathodes were prepared by submerging a silver foam in the etching solution for $10 \mathrm{~s}$ before the foam was retrieved and rinsed with deionized water.

\subsection{Scanning electron microscopy}

A FEI Helios NanoLab 650 dual beam scanning electron microscope was used to image silver foam cathodes before and after electrolysis. An accelerating voltage of $1.0 \mathrm{keV}$ and a beam current of 50 pA were used to image the top-view and cross-section of the samples. The silver foam thickness $(250$ $\mu \mathrm{m}$ ) was estimated using the cross-sectional image (Figure S2). 


\subsection{Electrolyzer design}

The bicarbonate electrolyzer used in this study was composed of two stainless-steel (316) housing pieces, a titanium anode flow plate, a stainless-steel (316) cathode flow plate, polytetrafluoroethylene (PTFE) gaskets, and a membrane-electrode assembly (MEA). This flow-by electrolyzer design was reported in our previous work. ${ }^{29}$ The MEA was composed of a nickel foam anode $\left(\right.$ geometric area $\left.=2 \times 2 \mathrm{~cm}^{2}\right)$, BPM (geometric area $\left.=2.5 \times 2.5 \mathrm{~cm}^{2}\right)$, and silver-foam cathode (geometric area $=2 \times 2 \mathrm{~cm}^{2}$ ). The anode and cathode flow plates were made with active areas of $4 \mathrm{~cm}^{2}$ $\left(2 \times 2 \mathrm{~cm}^{2}\right)$ and serpentine flow channels that are $1.5 \mathrm{~mm}$ wide and $1.5 \mathrm{~mm}$ deep with $1 \mathrm{~mm}$ ribs. The MEA and flowplates were sandwiched between the two stainless-steel housing pieces and 8 bolts were used to seal the electrolyzer to a compression of $5 \mathrm{~N} \cdot \mathrm{m}$.

\subsection{Electrolysis experiments}

All electrolysis experiments were performed at room temperature and pressure. Peristaltic pumps were used to deliver $1 \mathrm{M} \mathrm{KOH}$ to the anode compartment at a rate of $10 \mathrm{~mL} \mathrm{~min}^{-1}$ and $3 \mathrm{M} \mathrm{KHCO}_{3}$ to the cathode at a rate of $80 \mathrm{~mL} \mathrm{~min}{ }^{-1}$. A CH instrument 660D potentiostat (USA) with a complementary amp booster was used to apply constant current densities of $50,100,200$, and $300 \mathrm{~mA} \mathrm{~cm}^{-2}$ to the electrolyzer. Each current density was applied for 10 mins and the spent catholyte solution was replenished in between current density tests to counteract increases in alkalinity that occur during electrolysis. ${ }^{30}$ The $250 \mathrm{~mL}$ catholyte reservoir $\left(125 \mathrm{~mL} 3 \mathrm{M} \mathrm{KHCO}_{3} ; 125 \mathrm{~mL}\right.$ headspace) was continuously purged with $\mathrm{N}_{2}$ gas to deliver the cathodic reaction products to an in-line gas chromatograph (GC). GC measurements were performed for each current density after 5 minutes of electrolysis to saturate the electrolyte with products. ${ }^{30}$ As a control experiment, the catholyte headspace 
was analyzed using GC immediately before a current density was applied to the electrolyzer to quantify the baseline $\mathrm{CO}_{2}$ concentration. Triplicate measurements were performed using fresh materials (anode, cathode, and BPM) and bicarbonate solutions to determine experimental error bars. ${ }^{1} \mathrm{H}$ nuclear magnetic resonance experiments were performed on the anolyte and catholyte after 20 minutes of electrolysis, but no liquid $\mathrm{CO}_{2}$ reduction products (e.g., formate) were detected. The possibility of dilution influencing the quantification of liquid products was ruled out in control experiments performed with $50 \mathrm{~mL}$ electrolyte vessels (25 mL $3 \mathrm{M} \mathrm{KHCO}_{3} ; 25 \mathrm{~mL}$ headspace). The $\mathrm{GC}$ was equipped with a packed MolSieve 5 A column and a packed HaySep D column. A flame ionization detector (FID) with a methanizer was used to quantify the concentrations of $\mathrm{CO}, \mathrm{CO}_{2}, \mathrm{CH}_{4}$, and $\mathrm{C}_{2} \mathrm{H}_{4}$, while a thermal conductivity detector (TCD) was used to quantify the concentrations of $\mathrm{H}_{2}$. Argon was used as the carrier gas and the GC was calibrated by analyzing standard mixtures of $\mathrm{CO}$ and $\mathrm{H}_{2}$ at concentrations ranging from 100-50000 ppm. A flow controller purchased from AALBORG (USA) was used to set the $\mathrm{N}_{2}$ flow rate into the catholyte headspace at 170 standard cubic centimeters per minute. The flow rate at the GC outlet was measured using a flow indicator that was also purchased from AALBORG (USA). The GC and flow indicator measurements were used to determine the experimental faradaic efficiency and $\mathrm{CO}$ yields (as shown in the manuscript),

$$
\begin{gathered}
F E_{k}=\frac{n_{k} F x_{i} F_{m}}{I} \\
\mathrm{CO} \text { yield }=\frac{[\mathrm{CO}]}{\left[\mathrm{CO}_{2}\right] \text { outlet }+[\mathrm{CO}]}
\end{gathered}
$$

Where $n_{k}$ is the number of electrons transferred in reaction $k, I$ is the total current density, Fis Faraday's constant $\left(\mathrm{F}=96,485 \mathrm{C} \mathrm{mol}^{-1}\right), x_{j}$ is the mole fraction of gaseous species $j\left(j=\mathrm{CO}_{2}, \mathrm{H}_{2}, \mathrm{CO}\right.$, and $\mathrm{N}_{2}$ ) measured using the GC, $F_{m}$ is the total molar flow rate. The molar flow rate is derived from the 
volumetric flow rate $F_{v}$ (measured at the outlet of the GC) by the ideal gas equation of state ( $\left.F_{m}=P F_{v} / R T\right)$, with $P$ being the atmospheric pressure in $\mathrm{Pa}, R$ the ideal gas constant of $8.314 \mathrm{~J} / \mathrm{mol} \mathrm{K}$, and $T$ the temperature in $\mathrm{K}$. The $\left[\mathrm{CO}_{2}\right]_{\text {outlet }}$ and $[\mathrm{CO}]$ are the concentrations of $\mathrm{CO}_{2}$ and $\mathrm{CO}$ measured by the $\mathrm{GC}$ at the outlet of the catholyte reservoir. The $\left[\mathrm{CO}_{2}\right]_{\text {outlet }}$ measured during each electrolysis experiment was baseline corrected by subtracting the $\left[\mathrm{CO}_{2}\right]_{\text {outlet }}$ measured before a current density was applied (Fig. S3). This baseline correction compensates for $\mathrm{CO}_{2}$ that is naturally degassed from the electrolyte reservoir. ${ }^{31}$ 


\section{Supplementary Tables and Figures}

Table S1: Parameters used in the basecase model.

\begin{tabular}{|c|c|c|c|}
\hline Parameter & Value & Unit & $\begin{array}{c}\text { Reference } \\
\text { (in Supporting } \\
\text { Information) }\end{array}$ \\
\hline \multicolumn{4}{|c|}{ Operating Conditions } \\
\hline$T$ & 293.15 & $\mathrm{~K}$ & - \\
\hline$p^{0}$ & 1 & atm & - \\
\hline$u^{0}$ & 0.18 & $\mathrm{~m} \mathrm{~s}^{-1}$ & 30 \\
\hline$\phi_{s}^{0}$ & -1.5 to -2.1 & V & \\
\hline \multicolumn{4}{|l|}{ Geometry } \\
\hline$A_{c}$ & $7.5 \times 10^{-6}$ & $\mathrm{~m}^{2}$ & 31 \\
\hline$L_{\text {electrode }}$ & 0.02 & $\mathrm{~m}$ & 31 \\
\hline \multicolumn{4}{|l|}{ CL properties } \\
\hline$L_{C L}$ & 250 & $\mu \mathrm{m}$ & estimated \\
\hline$a_{v}$ & $4 \times 10^{4}$ & $\mathrm{~m}^{-1}$ & 18 \\
\hline$s_{C L}$ & 0.8 & - & estimated \\
\hline$\varepsilon_{C L}$ & 0.8 & - & 32 \\
\hline$r_{C L}$ & 5 & $\mu \mathrm{m}$ & 32 \\
\hline$\kappa_{s a t, C L}^{0}$ & $8 \times 10^{-16}$ & $\mathrm{~m}^{2}$ & 3 \\
\hline$\sigma_{s, C L}$ & 100 & $\mathrm{~S} \mathrm{~cm}^{-1}$ & 3 \\
\hline \multicolumn{4}{|l|}{ CEL properties } \\
\hline$L_{C E L}$ & 75 & $\mu \mathrm{m}$ & 32 \\
\hline$\rho_{M}$ & 1 & $\mathrm{~g} \mathrm{~mL}^{-1}$ & 13 \\
\hline$I E C$ & 1.99 & $\mathrm{mmol} \mathrm{g}^{-1}$ & 24 \\
\hline$q$ & 1 & - & 13 \\
\hline$\lambda_{H^{+}=1}$ & 9 & - & 13 \\
\hline$\lambda_{H^{+}=0}$ & 6 & - & 13 \\
\hline
\end{tabular}



$t_{H^{+}}$
0.9
13

Homogeneous

Reactions

$$
\begin{gathered}
k_{1} \\
K_{1} \\
k_{2} \\
K_{2} \\
k_{3} \\
k_{4} \\
K_{W}
\end{gathered}
$$

$$
\begin{gathered}
3.71 \times 10^{-2} \\
10^{-6.37} \\
59.44 \\
10^{-10.32} \\
2.23 \times 10^{3} \\
6.0 \times 10^{9} \\
10^{-14}
\end{gathered}
$$$$
\mathrm{s}^{-1}
$$$$
\text { M }
$$$$
\mathrm{s}^{-1}
$$$$
\text { M }
$$$$
\mathrm{L} \mathrm{mol}^{-1} \mathrm{~s}^{-1}
$$$$
L \mathrm{~mol}^{-1} \mathrm{~s}^{-1}
$$$$
M^{2}
$$

Electrochemical

\section{Reactions}

$\begin{array}{cccc}U_{C O 2 R R}^{0} & -0.11 & \mathrm{~V} & 3 \\ i_{0, C O 2 R R}^{0} & 1.1 \times 10^{9} & \mathrm{~mA} \mathrm{~cm}^{-2} & 3 \\ \alpha_{c, \text { CO2RR }} & 1 & - & 3 \\ c_{C O_{2}(a q)}^{r e f} & 1 & \mathrm{M} & 3 \\ U_{H E R}^{0} & 0 & \mathrm{~V} & 4 \\ i_{0, H E R}^{A} & 9.79 \times 10^{-4} & \mathrm{~mA} \mathrm{~cm}^{-2} & 4 \\ \alpha_{c, H E R}^{A} & 0.33 & - & 33,34 \\ i_{0, H E R}^{B} & 1.16 \times 10^{-6} & \mathrm{~mA} \mathrm{~cm}^{-2} & 4 \\ \alpha_{c, H E R}^{B} & 0.27 & - & 4 \\ c_{H^{+}}^{r e f} & 1 & \mathrm{M} & 4\end{array}$

Bulk concentrations in the liquid phase

$\begin{array}{lc}C_{\mathrm{H}^{+}}^{0} & 10^{-8.5} \\ C_{\mathrm{K}^{+}}^{0} & 3 \\ c_{\mathrm{OH}}^{0} & 10^{-5.5} \\ c_{\mathrm{HCO}_{3}^{-}}^{0} & 3 \\ C_{\mathrm{CO}_{3}^{2-}}^{0} & 0 \\ C_{\mathrm{CO}_{2}}^{0} & 0.008\end{array}$




$\begin{array}{llll}D_{H^{+}, w} & 9.31 \times 10^{-5} & \mathrm{~cm}^{2} \mathrm{~s}^{-1} & 36 \\ D_{K^{+}, w} & 1.96 \times 10^{-5} & \mathrm{~cm}^{2} \mathrm{~s}^{-1} & 36 \\ D_{O H^{-}, w} & 4.95 \times 10^{-5} & \mathrm{~cm}^{2} \mathrm{~s}^{-1} & 36 \\ D_{\mathrm{HCO}_{3}^{-}} & 1.19 \times 10^{-5} & \mathrm{~cm}^{2} \mathrm{~s}^{-1} & 36 \\ D_{\mathrm{CO}_{3}^{2-}} & 0.80 \times 10^{-5} & \mathrm{~cm}^{2} \mathrm{~s}^{-1} & 36 \\ D_{\mathrm{CO}_{2}(a q)} & 1.66 \times 10^{-5} & \mathrm{~cm}^{2} \mathrm{~s}^{-1} & 36\end{array}$

Gas phase transport

$\begin{array}{lllr}D_{\mathrm{H}_{2}-\mathrm{CO}} & 0.743 & \mathrm{~cm}^{2} \mathrm{~s}^{-1} & 4 \\ D_{\mathrm{H}_{2}-\mathrm{N}_{2}} & 0.779 & \mathrm{~cm}^{2} \mathrm{~s}^{-1} & 4 \\ D_{\mathrm{H}_{2}-\mathrm{CO}_{2}} & 0.646 & \mathrm{~cm}^{2} \mathrm{~s}^{-1} & 4 \\ D_{\mathrm{CO}-\mathrm{N}_{2}} & 0.202 & \mathrm{~cm}^{2} \mathrm{~s}^{-1} & 4 \\ D_{\mathrm{CO}-\mathrm{CO}_{2}} & 0.152 & \mathrm{~cm}^{2} \mathrm{~s}^{-1} & 4 \\ D_{\mathrm{N}_{2}-\mathrm{CO}_{2}} & 0.165 & \mathrm{~cm}^{2} \mathrm{~s}^{-1} & 4\end{array}$

Bulk concentrations in the gas phase

$\begin{array}{lcc}C_{\mathrm{H}_{2}}^{0} & 1.21 \times 10^{-5} & \mathrm{~mol} \mathrm{~m}^{-3} \\ c_{\mathrm{CO}}^{0} & 1.21 \times 10^{-5} & \mathrm{~mol} \mathrm{~m}^{-3} \\ c_{\mathrm{CO}_{2}}^{0} & 1.21 \times 10^{-5} & \mathrm{~mol} \mathrm{~m}^{-3} \\ C_{N_{2}}^{0} & 0.0241 & \mathrm{~mol} \mathrm{~m}^{-3}\end{array}$


Table S2. Modeled ionic concentrations and potentials at the AEL/CEL interface $(x=75 \mathrm{um})$ and sample Donnan equilibrium calculation using Eq. S7.

\begin{tabular}{|c|c|c|c|c|c|}
\hline \multirow{2}{*}{ Variables } & \multicolumn{5}{|c|}{$\mathrm{i}\left(\mathrm{mA} \mathrm{cm} \mathrm{cm}^{-2}\right)$} \\
\hline & 25 & 50 & 100 & 200 & 300 \\
\hline$\phi_{l, C E L}(\mathrm{~V})$ & -0.0042 & -0.0078 & -0.0136 & -0.0233 & -0.0330 \\
\hline$\phi_{l, C L}(\mathrm{~V})$ & 0.0017 & -0.0030 & -0.0098 & -0.0204 & -0.0304 \\
\hline$c_{K^{+}, C E L}(\mathrm{M})$ & 4.6710 & 5.1585 & 5.9052 & 6.9649 & 7.7008 \\
\hline$c_{K^{+}, C L}(\mathrm{M})$ & 3.6947 & 4.2616 & 5.0791 & 6.1953 & 6.9567 \\
\hline$c_{H^{+}, C E L}(\mathrm{M})$ & $2.1 \times 10^{-10}$ & $9.9 \times 10^{-11}$ & $4.6 \times 10^{-11}$ & $2.0 \times 10^{-11}$ & $1.1 \times 10^{-11}$ \\
\hline$c_{H^{+}, C L}(\mathrm{M})$ & $1.7 \times 10^{-10}$ & $8.1 \times 10^{-11}$ & $3.98 \times 10^{-11}$ & $1.8 \times 10^{-11}$ & $9.8 \times 10^{-12}$ \\
\hline$c_{\mathrm{HCO}_{3}^{-}, \mathrm{CEL}}(\mathrm{M})$ & 1.8675 & 1.6184 & 1.2822 & 0.8619 & 0.5855 \\
\hline$c_{\mathrm{HCO}_{3}^{-}, \mathrm{CL}}(\mathrm{M})$ & 2.3609 & 1.9590 & 1.4906 & 0.9688 & 0.6479 \\
\hline${ }^{C} \mathrm{CO}_{3}^{2-}, \mathrm{CEL}(\mathrm{M})$ & 0.4169 & 0.7850 & 1.3261 & 2.0655 & 2.5709 \\
\hline$c_{C O_{3}^{2-}, C L}(\mathrm{M})$ & 0.6669 & 1.1512 & 1.7941 & 2.6129 & 3.1539 \\
\hline$c_{O H^{-}, C E L}(\mathrm{M})$ & $4.7 \times 10^{-5}$ & $1.01 \times 10^{-4}$ & $2.2 \times 10^{-4}$ & $5.0 \times 10^{-4}$ & $9.2 \times 10^{-4}$ \\
\hline$c_{O H^{-}, C L}(\mathrm{M})$ & $5.9 \times 10^{-5}$ & $1.2 \times 10^{-4}$ & $2.51 \times 10^{-4}$ & $5.63 \times 10^{-4}$ & $1.0 \times 10^{-3}$ \\
\hline $\begin{array}{l}\text { Left-hand side of Eq. } \\
\qquad \mathbf{S 7}\end{array}$ & -0.0059 & -0.0048 & -0.0038 & -0.0030 & -0.0026 \\
\hline $\begin{array}{l}\text { Right-hand side of } \\
\text { Eq. } \mathbf{S 7} \text { for } \mathrm{i}=\mathrm{K}^{+}\end{array}$ & -0.0059 & -0.0048 & -0.0038 & -0.0030 & -0.0026 \\
\hline $\begin{array}{l}\text { Right-hand side of } \\
\text { Eq. } \mathbf{S 7} \text { for } \mathrm{i}=\mathrm{H}^{+}\end{array}$ & -0.0059 & -0.0049 & -0.0038 & -0.0030 & -0.0026 \\
\hline $\begin{array}{l}\text { Right-hand side of } \\
\text { Eq. S7 for } \mathrm{i}=\mathrm{HCO}_{3}^{-}\end{array}$ & -0.0059 & -0.0048 & -0.0038 & -0.0030 & -0.0026 \\
\hline $\begin{array}{l}\text { Right-hand side of } \\
\text { Eq. } \mathbf{S 7} \text { for } \mathrm{i}=\mathrm{CO}_{3}{ }^{2-}\end{array}$ & -0.0059 & -0.0048 & -0.0038 & -0.0030 & -0.0026 \\
\hline $\begin{array}{l}\text { Right-hand side of } \\
\text { Eq. } \mathbf{S 7} \text { for } \mathrm{i}=\mathrm{OH}^{-}\end{array}$ & -0.0059 & -0.0049 & -0.0038 & -0.0030 & -0.0026 \\
\hline$\%$ difference, $\mathrm{K}^{+}$ & $0.01 \%$ & $0.05 \%$ & $0.14 \%$ & $0.22 \%$ & $0.17 \%$ \\
\hline$\%$ difference, $\mathrm{H}^{+}$ & $0.40 \%$ & $0.63 \%$ & $0.70 \%$ & $1.77 \%$ & $2.87 \%$ \\
\hline$\%$ difference, $\mathrm{HCO}_{3}^{-}$ & $0.02 \%$ & $0.02 \%$ & $0.20 \%$ & $0.10 \%$ & $0.59 \%$ \\
\hline$\%$ difference, $\mathrm{CO}_{3}{ }^{2-}$ & $0.17 \%$ & $0.28 \%$ & $0.15 \%$ & $0.61 \%$ & $0.40 \%$ \\
\hline$\%$ difference, $\mathrm{OH}^{-}$ & $0.40 \%$ & $0.63 \%$ & $0.71 \%$ & $1.78 \%$ & $2.89 \%$ \\
\hline
\end{tabular}


Table S3: Equilibrium concentrations for the AEL/CEL mass flux boundary condition used to produce the model results in Fig. S9. The concentrations of each species were computed as a function of $\mathrm{pH}$ at a constant carbon concentration of $3 \mathrm{M}$ using pKa values of 6.37 and 10.32 for $\mathrm{HCO}_{3}{ }^{-}$and $\mathrm{CO}_{3}{ }^{2-}$, respectively.

\begin{tabular}{ccccc}
\hline $\mathrm{pH}$ & $\begin{array}{c}\mathrm{CO}_{2} \\
(\mathrm{mM})\end{array}$ & $\begin{array}{c}\mathrm{HCO}_{3}^{-} \\
(\mathrm{M})\end{array}$ & $\begin{array}{c}\mathrm{CO}_{3}^{2-} \\
(\mathrm{M})\end{array}$ & $\begin{array}{c}\mathrm{K}^{+} \\
(\mathrm{M})\end{array}$ \\
\hline 9 & 5.7 & 2.9 & 0.1 & 3.1 \\
9.5 & 1.6 & 2.6 & 0.4 & 3.4 \\
10 & 0.4 & 2.0 & 1.0 & 4.0
\end{tabular}

\section{Gas-fed $\mathrm{CO}_{2}$ electrolysis}

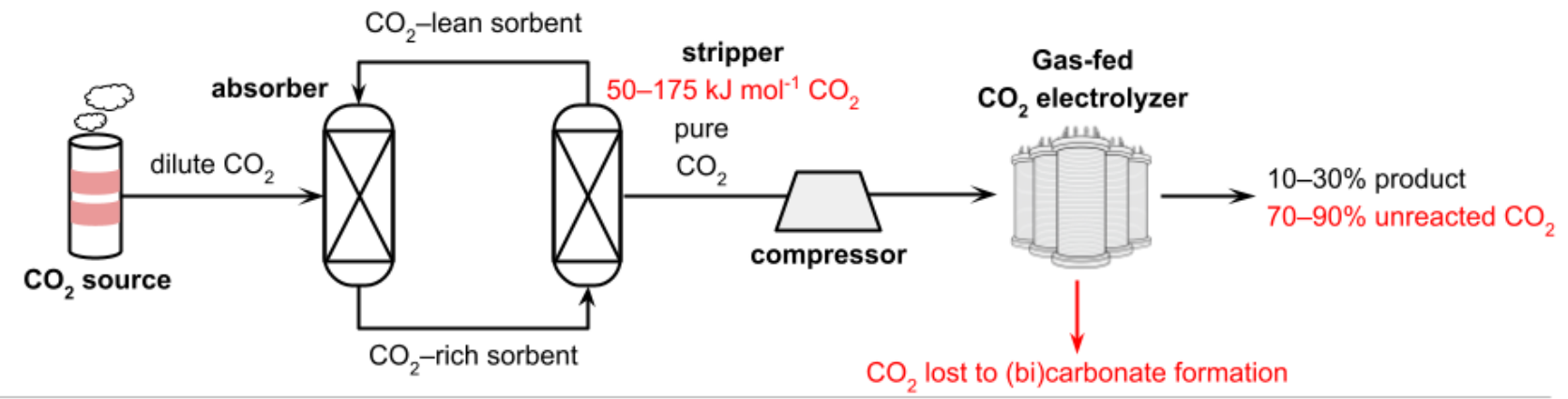

Bicarbonate electrolysis

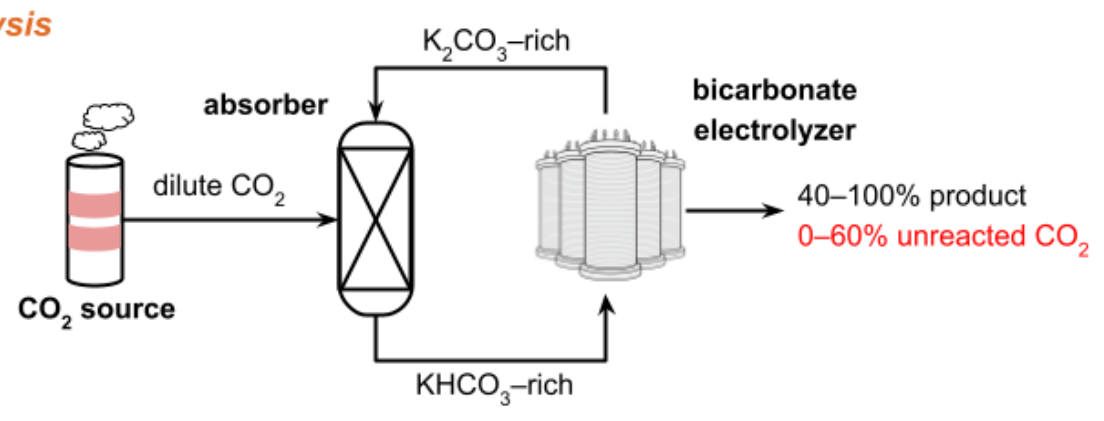

Figure S1: Flow diagrams for $\mathrm{CO}_{2}$ capture and $\mathrm{CO}_{2}$ reduction using a gas-fed $\mathrm{CO}_{2}$ electrolyzer (top) and a bicarbonate electrolyzer (bottom). In both pathways, $\mathrm{CO}_{2}$ from a $\mathrm{CO}_{2}$ source is captured by a reactive absorption process that converts $\mathrm{K}_{2} \mathrm{CO}_{3}$ into $\mathrm{KHCO}_{3}$. Gas-fed $\mathrm{CO}_{2}$ electrolyzers require energy to generate pure $\mathrm{CO}_{2}$ and regenerate the sorbent. The energy range reported is based on the minimum reboiler duty for liquid absorption processes ${ }^{37,38}$ and direct air capture ${ }^{39}$. The single pass conversion efficiencies represent values commonly reported for gas-fed $\mathrm{CO}_{2}$ electrolyzers. ${ }^{40-43}$ A bicarbonate electrolyzer does not require $\mathrm{CO}_{2}$ stripping or compression and instead produces $\mathrm{CO}$ directly from $\mathrm{KHCO}_{3}$ while regenerating the $\mathrm{K}_{2} \mathrm{CO}_{3}$ sorbent. ${ }^{44} \mathrm{CO}$ yields ranging from $40-70 \%$ have been reported for bicarbonate electrolyzers. ${ }^{30}$ 
a

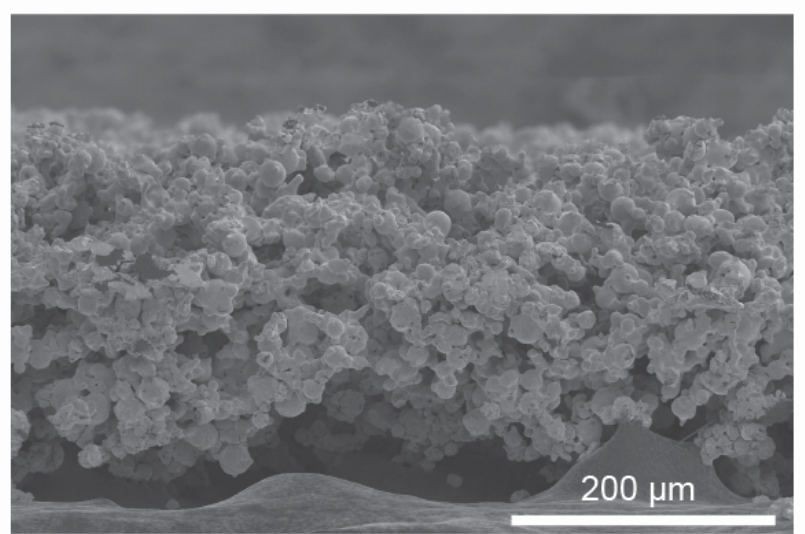

C

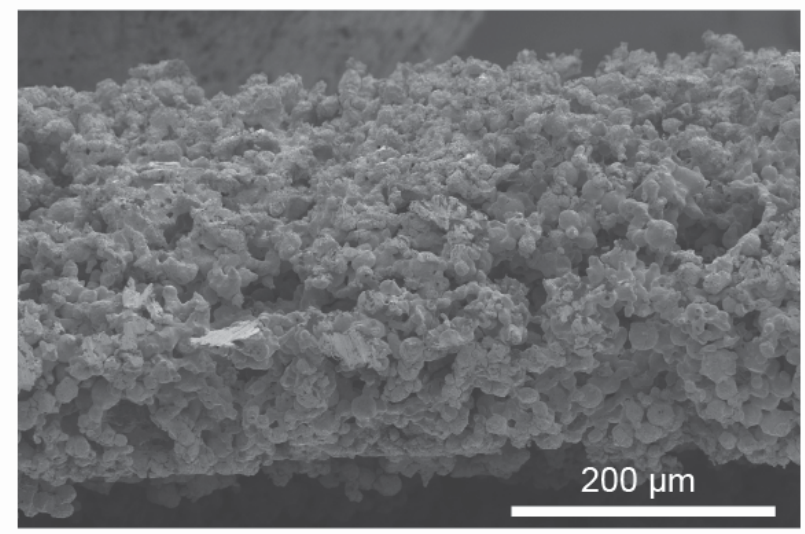

b

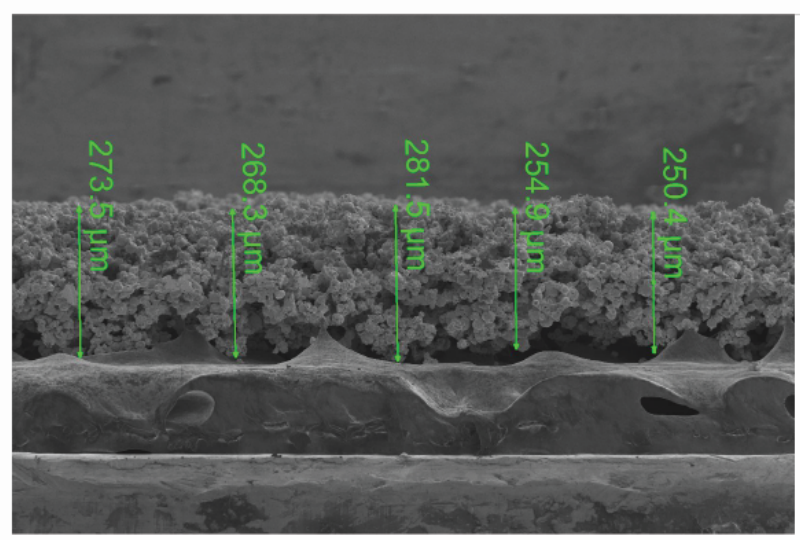

d

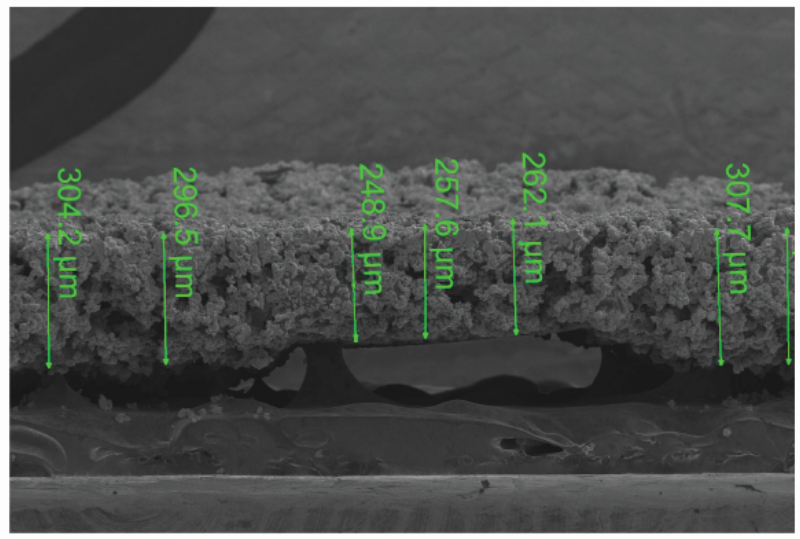

Figure S2: Scanning electron microscopy images of silver foam cathodes before and after electrolysis. (a) Top-view and cross-sectional (b) images of a silver foam cathode showing the morphology and thickness before electrolysis. (c) Top-view and cross-sectional (d) images of the silver foam cathode after electrolysis. Pressure from electrolyzer construction and testing was observed to expand and compress the silver foam at the flow plate channels and landings, respectively. 


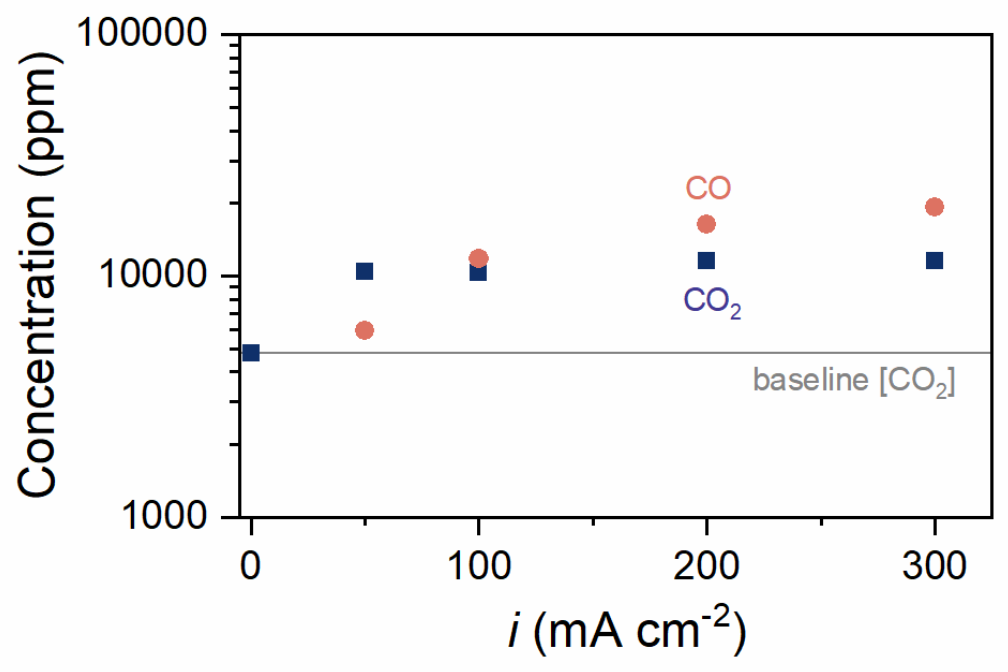

Figure S3: Gas chromatograph (GC) data showing the concentration of $\mathrm{CO}$ and $\mathrm{CO}_{2}$ as a function of current density. The baseline $\left[\mathrm{CO}_{2}\right]$ was measured at $0 \mathrm{~mA} \mathrm{~cm}^{-2}$ while circulating the catholyte and anolyte to the electrolyzer and sweeping $\mathrm{N}_{2}$ gas through the catholyte reservoir headspace.

$$
\text { Overall: } 2 \mathrm{HCO}_{3}{ }^{-} \rightarrow \mathrm{CO}+\mathrm{CO}_{3}{ }^{2-}+\mathrm{H}_{2} \mathrm{O}+1 / 2 \mathrm{O}_{2}
$$

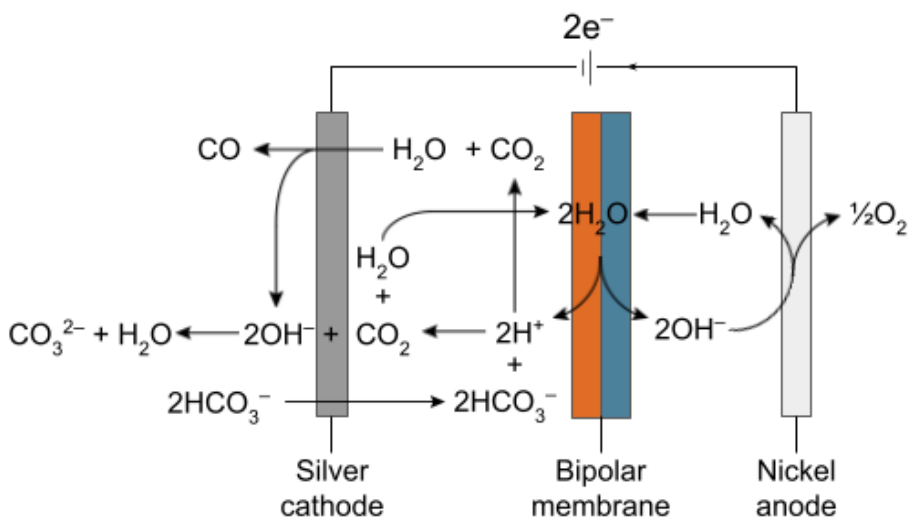

Figure S4: Schematic diagram of the stoichiometry for the dominant reaction pathway in the bicarbonate electrolyzer. This pathway gives rise to an optimal $\mathrm{CO}$ yield of $100 \%$ and is based on the assumptions of: (1) $100 \% \mathrm{FE}_{\mathrm{CO}}$; (2) complete conversion of $\mathrm{CO}_{2}$ and $\mathrm{OH}^{-}$into $\mathrm{CO}_{3}^{-}$. 


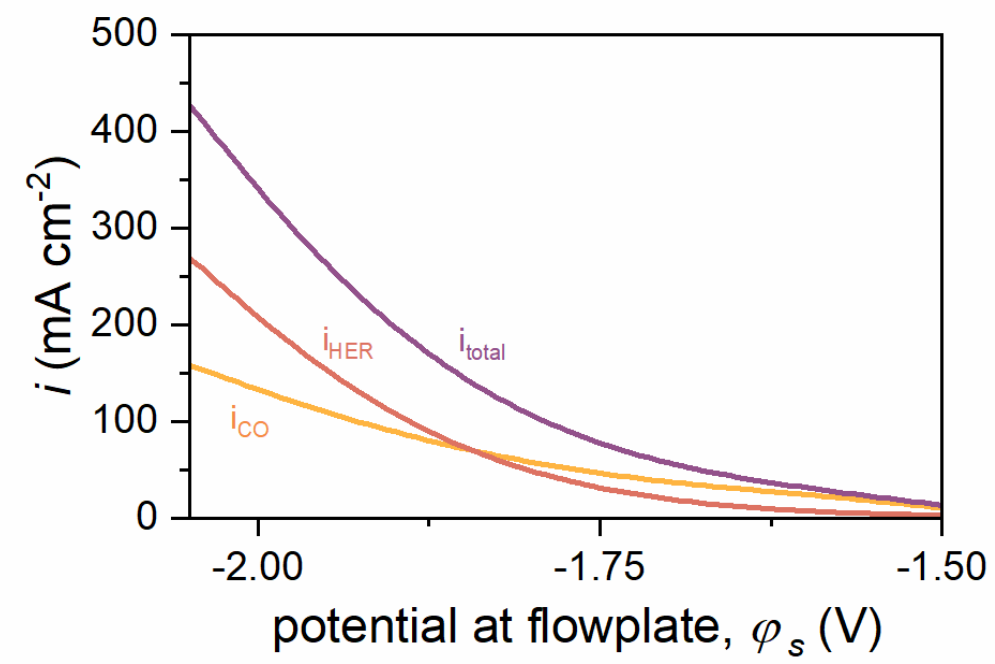

Figure S5: Modeled total current densities $\left(i_{\text {total }}\right)$ and partial current densities for $\mathrm{CO}$ formation $\left(i_{\mathrm{CO}}\right)$ and hydrogen evolution reaction $\left(i_{\mathrm{HER}}\right)$ as a function of the solid-phase potential $\left(\boldsymbol{\varphi}_{\mathrm{s}}\right) \mathrm{vs}$. SHE. The potential is reported at the $\mathrm{CL} /$ flow plate interface relative to the arbitrary reference potential of $0 \mathrm{~V}$ at the AEL/CEL interface.

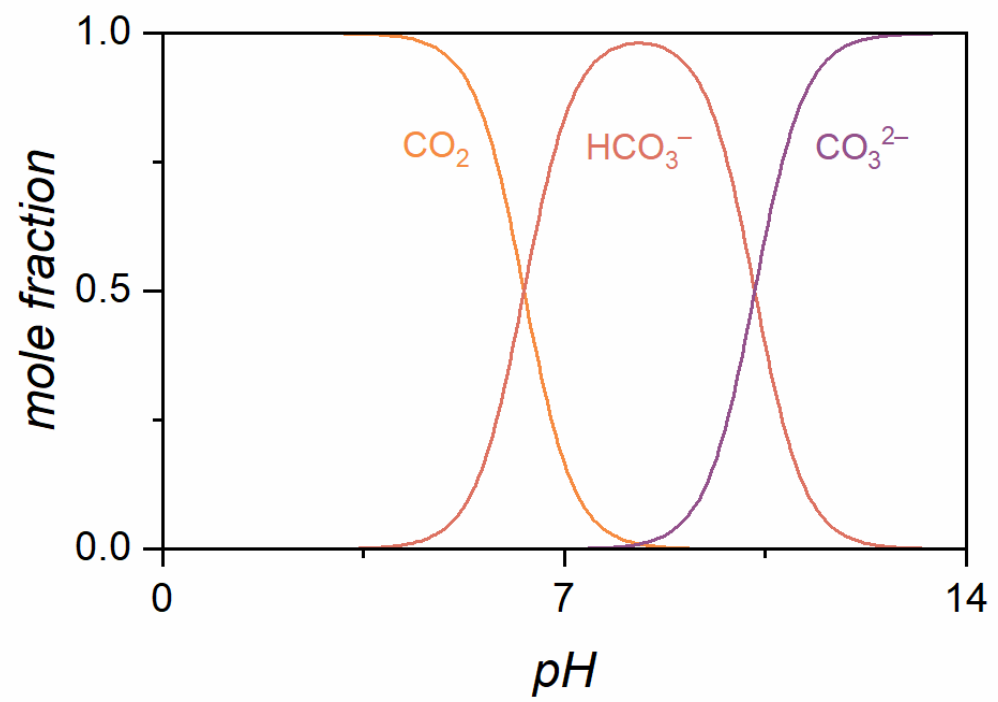

Figure S6: The thermodynamic equilibrium of (bi)carbonates and $\mathrm{CO}_{2}$ in aqueous media (Bjerrum plot). Mole fractions for $\mathrm{CO}_{2(\mathrm{aq})}, \mathrm{HCO}_{3}^{-}$(aq) , and $\mathrm{CO}_{3}^{-}$(aq) as a function of $\mathrm{pH}$ at ambient conditions (temperature $=25^{\circ} \mathrm{C}$; pressure $=1 \mathrm{~atm}$ ). 

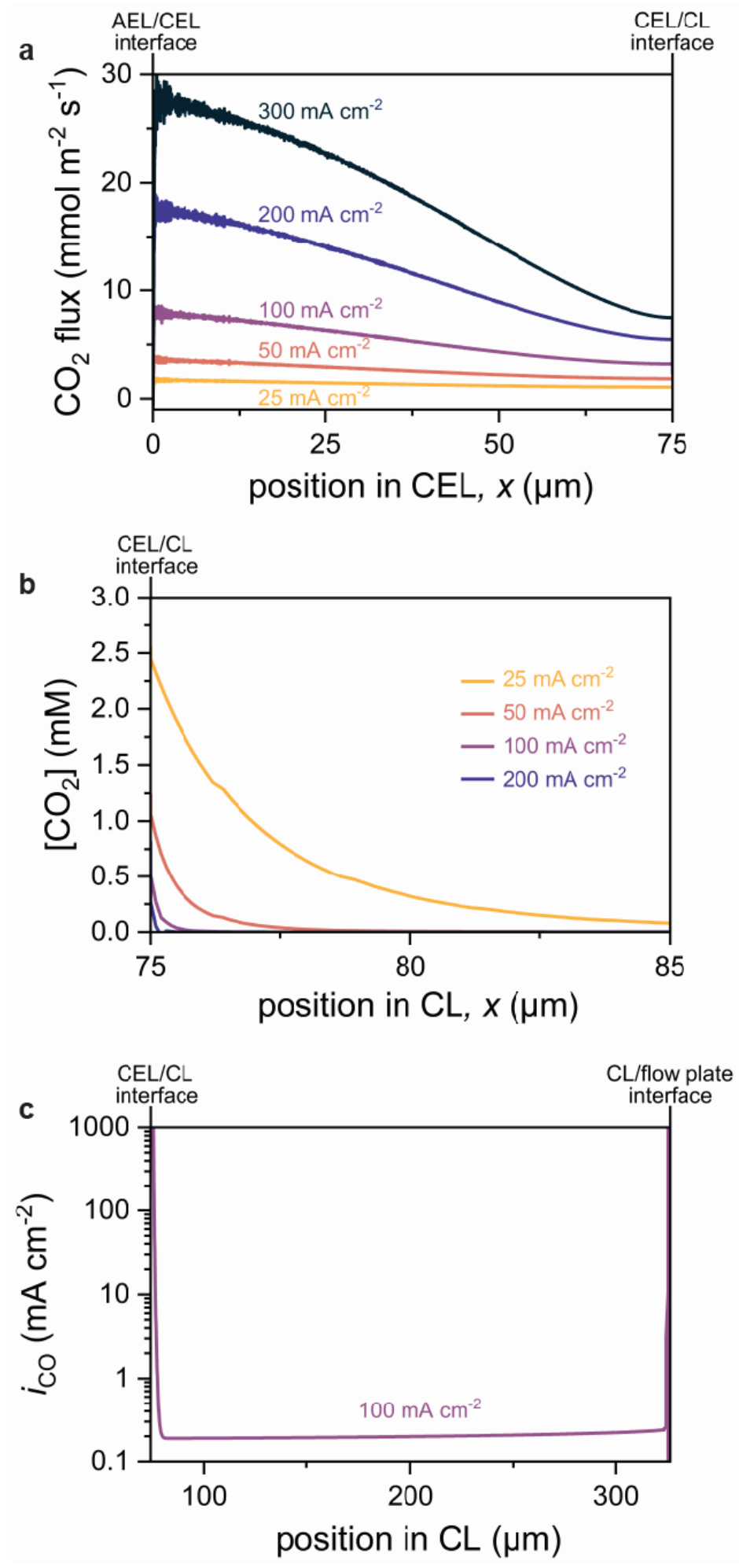

Figure S7: Modeling results which demonstrate the generation and transport of $\mathrm{CO}_{2}$ from the CEL to the CL. (a) Net molar $\mathrm{CO}_{2}$ fluxes for different current densities in the CEL. Positive values indicate a net molar $\mathrm{CO}_{2}$ flux in the positive $x$ direction (i.e., towards the $\mathrm{CL}$ ). (b) $\mathrm{CO}_{2}$ concentration profiles as a function of current density for the CL region near the CEL/CL interface (i.e., $x=75-85 \mu \mathrm{m}$ ). Note that the entire model domain is plotted in Figure 2. (c) Partial current densities for $\mathrm{CO}\left(i_{\mathrm{CO}}\right)$ as a function of position in the $\mathrm{CL}$ at $100 \mathrm{~mA} \mathrm{~cm}{ }^{-2}$. 

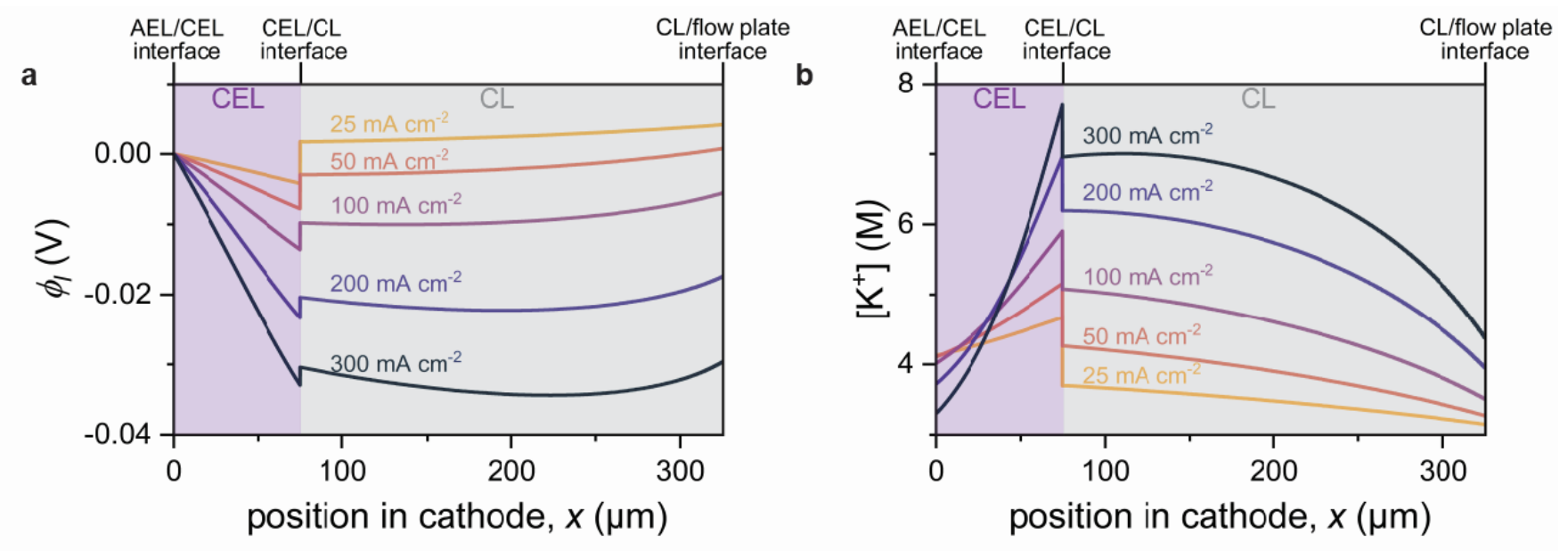

Figure S8: Modeled (a) electrolyte potential and (b) $\mathrm{K}^{+}$concentration profiles within the cathode CEL and CL of the bicarbonate electrolyzer as a function of total current density. Shaded regions indicate the location of the CEL (purple; $x=0-75 \mu \mathrm{m}$ ) and CL (grey; $x=75-325 \mu \mathrm{m}$ ).

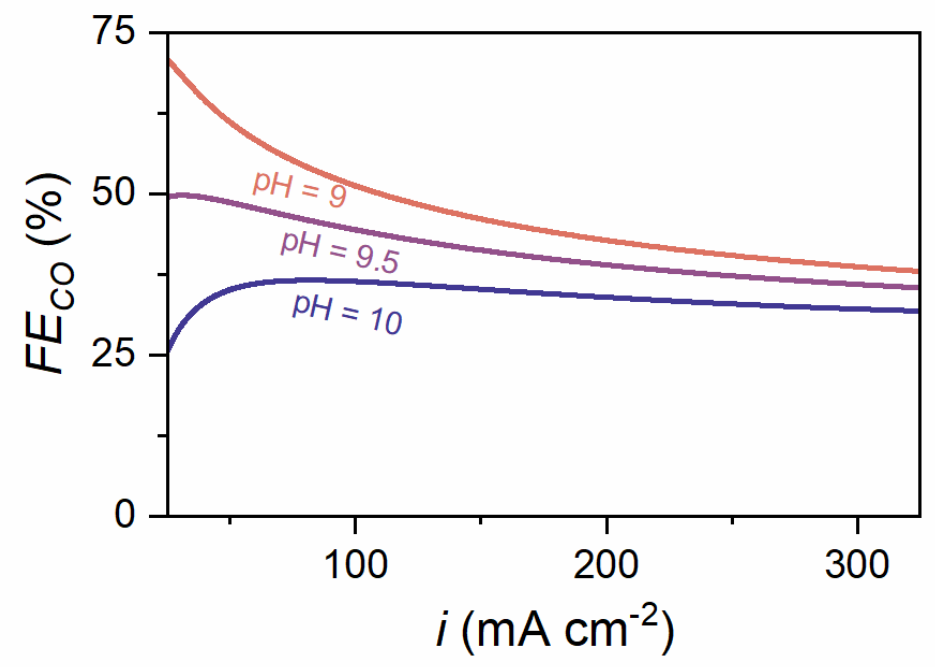

Figure S9: Modeling results which demonstrate the effect of the $\mathrm{pH}$ boundary condition at the $\mathrm{CL} /$ flowplate interface on $F E_{C O}$ over a range of current densities. 


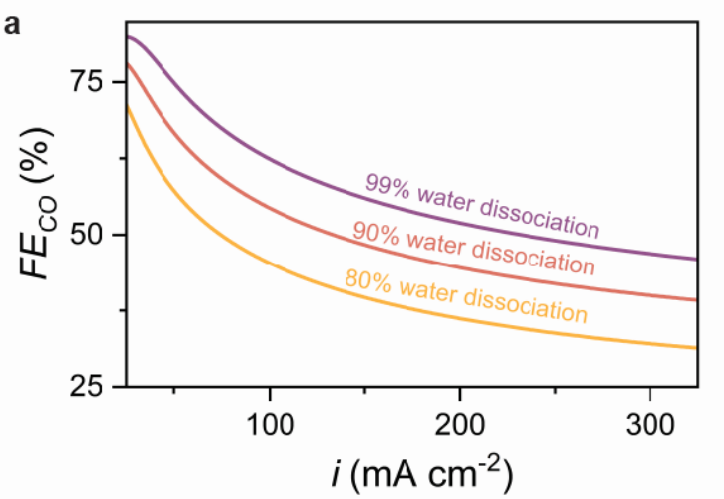

b
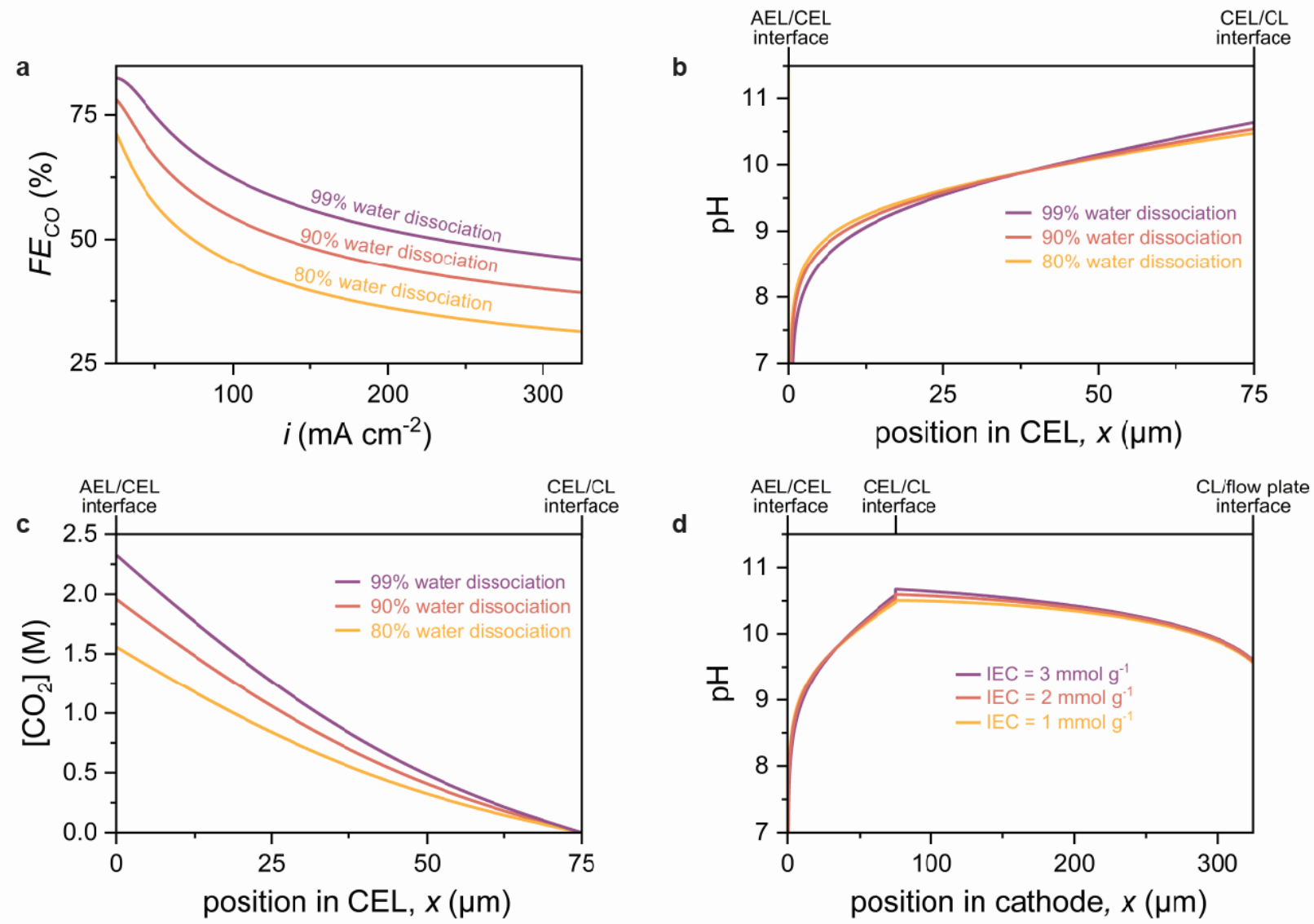

Figure S10: Sensitivity analyses demonstrating the predicted effects of water dissociation rates and IEC of the CEL on bicarbonate electrolysis. Modeling results show that increasing the rate of water dissociation increases the (a) $F E_{C O}$ by decreasing the (b) $\mathrm{pH}$ in the CEL and increasing the (c) $\mathrm{CO}_{2}$ concentration in the CEL. (d) An increase in IEC increases the local $\mathrm{pH}$ in the CL. The $\mathrm{CO}_{2}$ concentration and $\mathrm{pH}$ profiles are reported at a constant total current density of $150 \mathrm{~mA} \mathrm{~cm}$. 

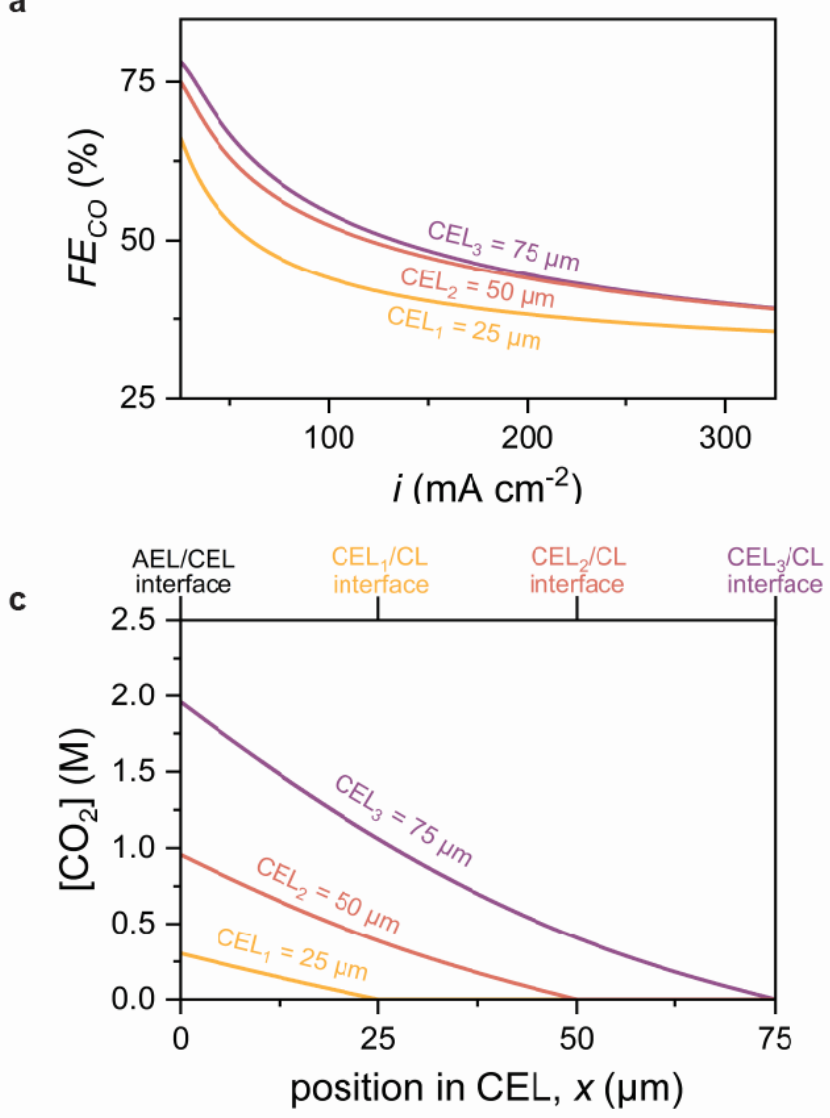
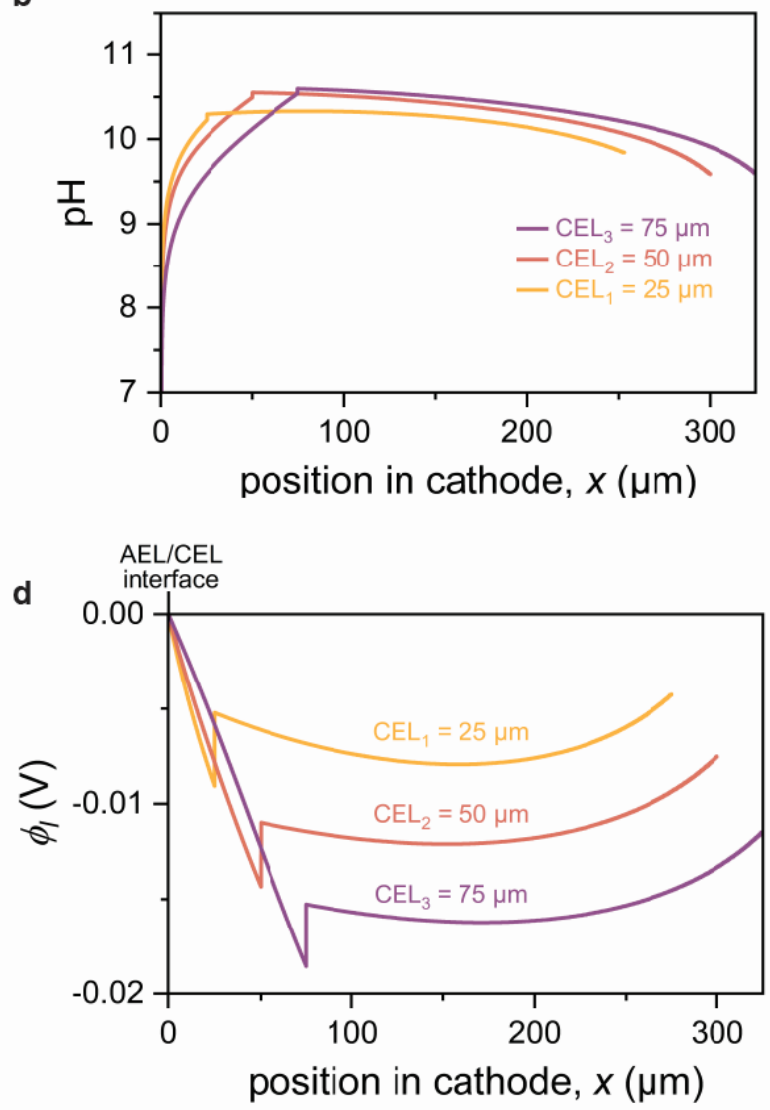

Figure S11: Sensitivity analyses demonstrating the predicted effects of CEL thickness on bicarbonate electrolysis. Modeling results show that increasing the CEL thickness increases the (a) $F E_{C O}$. (b) Increasing CEL thickness decreases the $\mathrm{pH}$ in the CEL, but increases the $\mathrm{pH}$ in the CL. (c) The $\mathrm{CO}_{2}$ concentration in the CEL increases with increasing CEL thickness. (d) The electrolyte potential $\left(\phi_{l}\right)$ drop increases with increasing CEL thickness. The $\mathrm{CO}_{2}$ concentration, $\mathrm{pH}$, and electrolyte potential profiles are reported at a constant total current density of $150 \mathrm{~mA} \mathrm{~cm}$. 

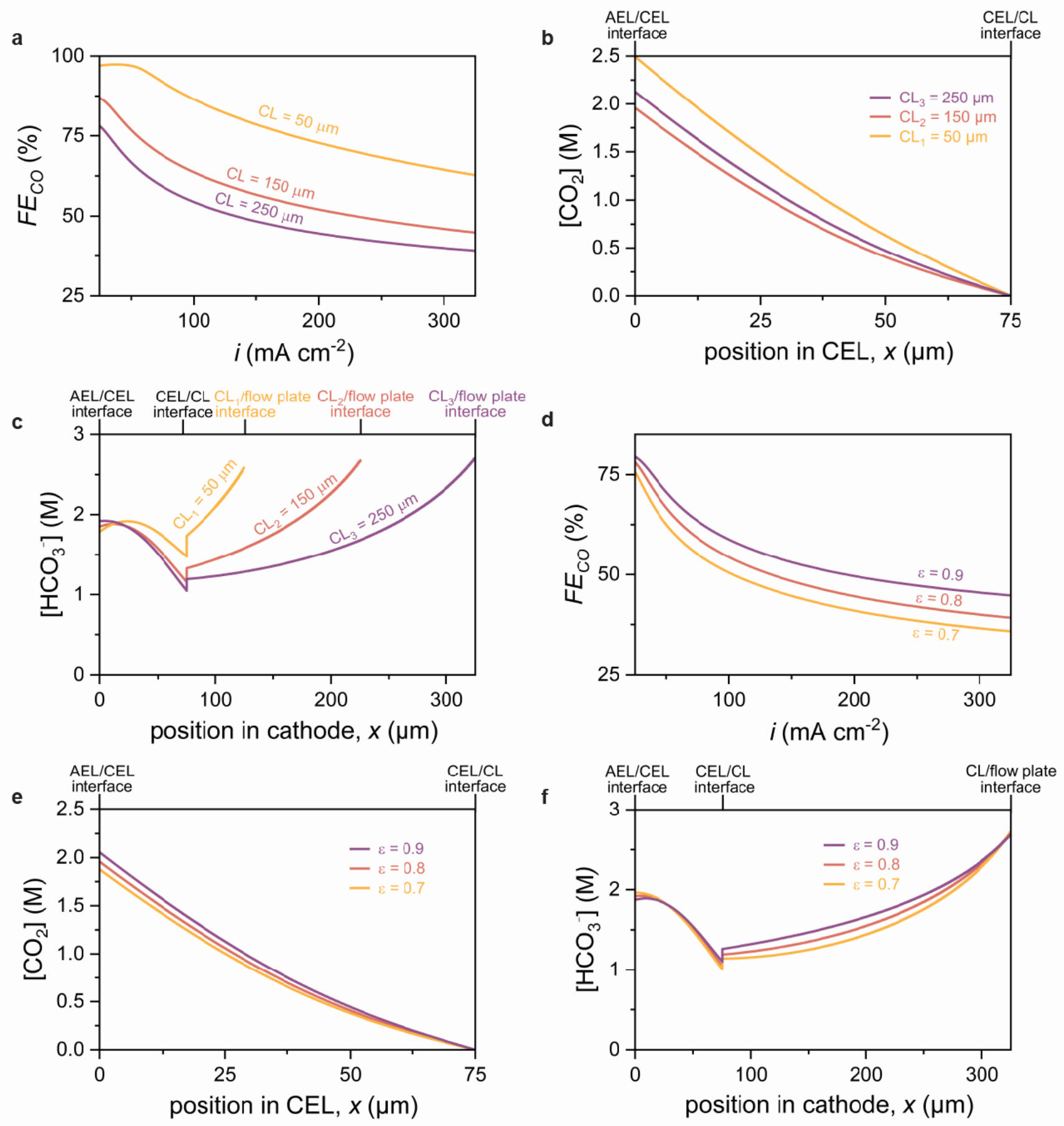

Figure S12: Sensitivity analyses demonstrating the predicted effect of CL properties on bicarbonate electrolysis. Modeling results show that increasing the CL thickness increases the (a) $F E_{C O}$. An increase in CL thickness also increases the (b) $\mathrm{CO}_{2}$ concentration in the CEL and (c) $\mathrm{HCO}_{3}{ }^{-}$ concentration in the CL. The modeling results show that increasing the porosity $(\varepsilon)$ increases $(d)$ $F E_{C O}$, (e) $\mathrm{CO}_{2}$ concentration in the CEL, and (f) $\mathrm{HCO}_{3}{ }^{-}$concentration in the CL. The $\mathrm{CO}_{2}$ and $\mathrm{HCO}_{3}^{-}$concentration profiles are reported at a constant total current density of $150 \mathrm{~mA} \mathrm{~cm}{ }^{-2}$. 


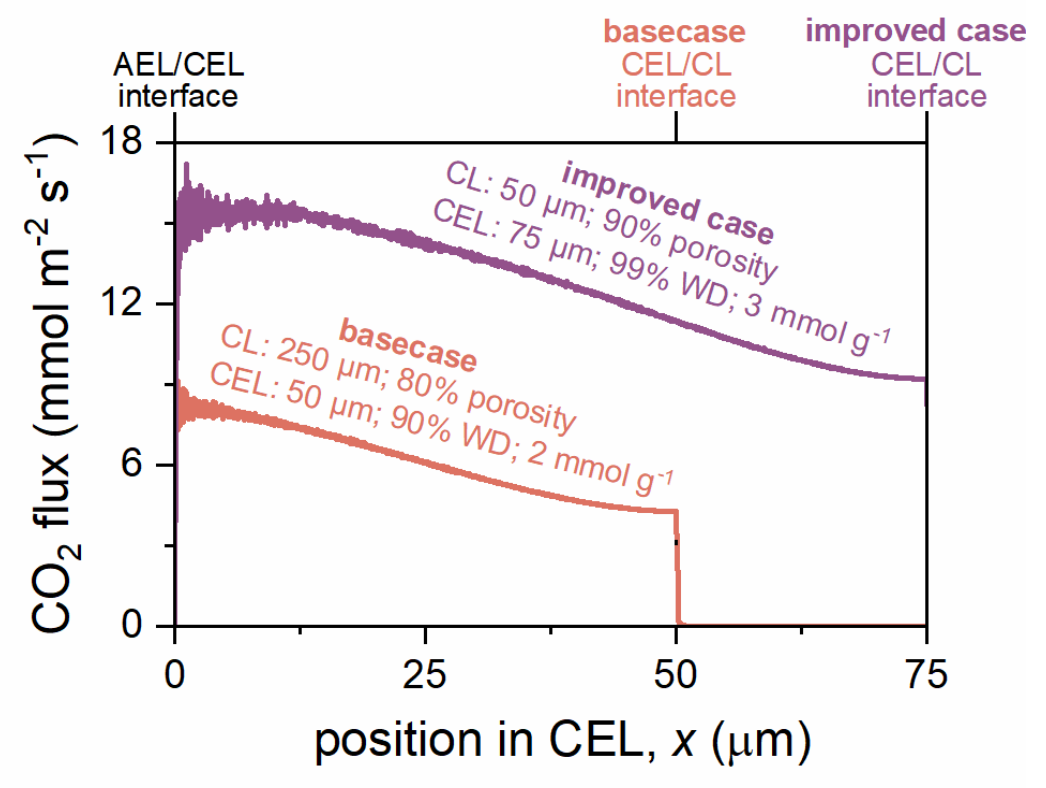

Figure S13: Modeled $\mathrm{CO}_{2}$ fluxes for the improved CEL and CL properties $\left(99 \% \mathrm{H}^{+}\right.$flux; CEL thickness $=75 \mu \mathrm{m} ;$ IEC $=3 \mathrm{mmol} \mathrm{g}^{-1} ; \mathrm{CL}$ porosity $=0.9 ; \mathrm{CL}$ thickness $\left.=50 \mu \mathrm{m}\right)$ and the basecase properties $\left(90 \% \mathrm{H}^{+}\right.$flux; CEL thickness $=50 \mu \mathrm{m}$; IEC $=2 \mathrm{mmol} \mathrm{g}^{-1}$; CL porosity $=0.8 ; \mathrm{CL}$ thickness $=250 \mu \mathrm{m})$ at a constant current density of $150 \mathrm{~mA} \mathrm{~cm}^{-2}$. 


\section{References}

(1) Seifitokaldani, A.; Gabardo, C. M.; Burdyny, T.; Dinh, C.-T.; Edwards, J. P.; Kibria, M. G.; Bushuyev, O. S.; Kelley, S. O.; Sinton, D.; Sargent, E. H. Hydronium-Induced Switching between CO2 Electroreduction Pathways. J. Am. Chem. Soc. 2018, 140 (11), 3833-3837.

(2) Lees, E. W.; Mowbray, B. A. W.; Salvatore, D. A.; Simpson, G. L.; Dvorak, D. J.; Ren, S.; Chau, J.; Milton, K. L.; Berlinguette, C. P. Linking Gas Diffusion Electrode Composition to $\mathrm{CO}_{2}$ Reduction in a Flow Cell. J. Mater. Chem. A. 2020, 8 (37), 19493-19501.

(3) Weng, L.-C.; Bell, A. T.; Weber, A. Z. Towards Membrane-Electrode Assembly Systems for CO 2 Reduction: A Modeling Study. Energy Environ. Sci. 2019, 12 (6), 1950-1968.

(4) Weng, L.-C.; Bell, A. T.; Weber, A. Z. Modeling Gas-Diffusion Electrodes for $\mathrm{CO}_{2}$ Reduction. Phys. Chem. Chem. Phys. 2018, 20 (25), 16973-16984.

(5) Mafé, S.; Ramírez, P.; Alcaraz, A. Electric Field-Assisted Proton Transfer and Water Dissociation at the Junction of a Fixed-Charge Bipolar Membrane. Chem. Phys. Lett. 1998, 294 (4), 406-412.

(6) Mafé, S.; Ramírez, P. Electrochemical Characterization of Polymer Ion-Exchange Bipolar Membranes. Acta Polym. 1997, 48 (7), 234-250.

(7) McDonald, M. B.; Ardo, S.; Lewis, N. S.; Freund, M. S. Use of Bipolar Membranes for Maintaining Steady-State $\mathrm{pH}$ Gradients in Membrane-Supported, Solar-Driven Water Splitting. ChemSusChem 2014, 7 (11), 3021-3027.

(8) McDonald, M. B.; Freund, M. S.; Hammond, P. T. Catalytic, Conductive Bipolar Membrane Interfaces through Layer-by-Layer Deposition for the Design of Membrane-Integrated Artificial Photosynthesis Systems. ChemSusChem 2017, 10 (22), 4599-4609.

(9) McDonald, M. B.; Bruce, J. P.; McEleney, K.; Freund, M. S. Reduced Graphene Oxide Bipolar Membranes for Integrated Solar Water Splitting in Optimal pH. ChemSusChem 2015, 8 (16), 2645-2654.

(10) Oener, S. Z.; Foster, M. J.; Boettcher, S. W. Accelerating Water Dissociation in Bipolar Membranes and for Electrocatalysis. Science 2020, 369 (6507), 1099-1103.

(11) Shen, C.; Wycisk, R.; Pintauro, P. N. High Performance Electrospun Bipolar Membrane with a 3D Junction. Energy Environ. Sci. 2017, 10 (6), 1435-1442.

(12) Mareev, S. A.; Evdochenko, E.; Wessling, M.; Kozaderova, O. A.; Niftaliev, S. I.; Pismenskaya, N. D.; Nikonenko, V. V. A Comprehensive Mathematical Model of Water Splitting in Bipolar Membranes: Impact of the Spatial Distribution of Fixed Charges and Catalyst at Bipolar Junction. J. Memb. Sci. 2020, 603, 118010.

(13) Bui, J. C.; Digdaya, I.; Xiang, C.; Bell, A. T.; Weber, A. Z. Understanding Multi-Ion Transport Mechanisms in Bipolar Membranes. ACS Appl. Mater. Interfaces 2020, 12 (47), 52509-52526.

(14) Blommaert, M. A.; Verdonk, J. A. H.; Blommaert, H. C. B.; Smith, W. A.; Vermaas, D. A. Reduced Ion Crossover in Bipolar Membrane Electrolysis via Increased Current Density, Molecular Size, and Valence. ACS Appl. Energy Mater. 2020, 3 (6), 5804-5812.

(15) Nishida, K.; Murakami, T.; Tsushima, S.; Hirai, S. Measurement of Liquid Water Content in Cathode Gas Diffusion Electrode of Polymer Electrolyte Fuel Cell. J. Power Sources 2010, 195 (11), 3365-3373.

(16) Angulo, A.; van der Linde, P.; Gardeniers, H.; Modestino, M.; Fernández Rivas, D. Influence of Bubbles on the Energy Conversion Efficiency of Electrochemical Reactors. Joule 2020, 4 (3), 555-579.

(17) Nesbitt, N. T.; Burdyny, T.; Simonson, H.; Salvatore, D.; Bohra, D.; Kas, R.; Smith, W. A. Liquid-solid Boundaries Dominate Activity of CO2 Reduction on Gas-Diffusion Electrodes. $A C S$ 
Catal. 2020, 10 (23), 14093-14106.

(18) Liu, P. S. A New Method for Calculating the Specific Surface Area of Porous Metal Foams. Philos. Mag. Lett. 2010, 90 (6), 447-453.

(19) Jähne, B.; Heinz, G.; Dietrich, W. Measurement of the Diffusion Coefficients of Sparingly Soluble Gases in Water. J. Geophys. Res. 1987, 92 (C10), 10767.

(20) Zenyuk, I. V.; Medici, E.; Allen, J.; Weber, A. Z. Coupling Continuum and Pore-Network Models for Polymer-Electrolyte Fuel Cells. Int. J. Hydrogen Energy 2015, 40 (46), 16831-16845.

(21) Weber, A. Z.; Newman, J. Modeling Transport in Polymer-Electrolyte Fuel Cells. Chem. Rev. 2004, 104 (10), 4679-4726.

(22) Delacourt, C.; Ridgway, P. L.; Kerr, J. B.; Newman, J. Design of an Electrochemical Cell Making Syngas $\left(\mathrm{CO}+\mathrm{H}_{2}\right)$ from $\mathrm{CO}_{2}$ and $\mathrm{H}_{2} \mathrm{O}$ Reduction at Room Temperature. J. Electrochem. Soc. 2008, 155 (1), B42-B49.

(23) Zhang, Z.; Melo, L.; Jansonius, R. P.; Habibzadeh, F.; Grant, E. R.; Berlinguette, C. P. pH Matters When Reducing CO2 in an Electrochemical Flow Cell. ACS Energy Lett. 2020, 5 (10), 3101-3107.

(24) Knehr, K. W.; Agar, E.; Dennison, C. R.; Kalidindi, A. R.; Kumbur, E. C. A Transient Vanadium Flow Battery Model Incorporating Vanadium Crossover and Water Transport through the Membrane. J. Electrochem. Soc. 2012, 159 (9), A1446.

(25) Vermaas, D. A.; Wiegman, S.; Nagaki, T.; Smith, W. A. Ion Transport Mechanisms in Bipolar Membranes for (photo)electrochemical Water Splitting. Sustainable Energy Fuels 2018, 2 (9), 2006-2015.

(26) Grew, K. N.; Chiu, W. K. S. A Dusty Fluid Model for Predicting Hydroxyl Anion Conductivity in Alkaline Anion Exchange Membranes. J. Electrochem. Soc. 2010, 157 (3), B327.

(27) Wang, X.; Van Nguyen, T.; Hussey, D. S.; Jacobson, D. L. An Experimental Study of Relative Permeability of Porous Media Used in Proton Exchange Membrane Fuel Cells. J. Electrochem. Soc. 2010, 157 (12), B1777.

(28) He, J.; Huang, A.; Johnson, N. J. J.; Dettelbach, K. E.; Weekes, D. M.; Cao, Y.; Berlinguette, C. P. Stabilizing Copper for $\mathrm{CO}_{2}$ Reduction in Low-Grade Electrolyte. Inorg. Chem. 2018.

(29) Salvatore, D. A.; Weekes, D. M.; He, J.; Dettelbach, K. E.; Li, Y. C.; Mallouk, T. E.; Berlinguette, C. P. Electrolysis of Gaseous $\mathrm{CO} 2$ to $\mathrm{CO}$ in a Flow Cell with a Bipolar Membrane. ACS Energy Lett. 2018, 3 (1), 149-154.

(30) Lees, E. W.; Goldman, M.; Fink, A. G.; Dvorak, D. J.; Salvatore, D. A.; Zhang, Z.; Loo, N. W. X.; Berlinguette, C. P. Electrodes Designed for Converting Bicarbonate into CO. ACS Energy Lett. 2020, 5 (7), 2165-2173.

(31) Li, T.; Lees, E. W.; Goldman, M.; Salvatore, D. A.; Weekes, D. M.; Berlinguette, C. P. Electrolytic Conversion of Bicarbonate into CO in a Flow Cell. Joule 2019, 3 (6), 1487-1497.

(32) Zhang, Z.; Lees, E. W.; Habibzadeh, F.; Salvatore, D. A.; Ren, S.; Simpson, G.; Wheeler, D. G.; Liu, A.; Berlinguette, C. P. Metallic Porous Electrodes Enable Efficient Bicarbonate Electrolysis. ChemRxiv 2021.

(33) Campbell, F. W.; Belding, S. R.; Baron, R.; Xiao, L.; Compton, R. G. The Hydrogen Evolution Reaction at a Silver Nanoparticle Array and a Silver Macroelectrode Compared: Changed Electrode Kinetics between the Macro- and Nanoscales. J. Phys. Chem. C 2009, 113 (33), 14852-14857.

(34) Krishtalik, L. I. Charge Transfer Reactions in Electrochemical and Chemical Processes; Springer Science \& Business Media, 2012.

(35) Min, X.; Kanan, M. W. Pd-Catalyzed Electrohydrogenation of Carbon Dioxide to Formate: High Mass Activity at Low Overpotential and Identification of the Deactivation Pathway. J. Am. Chem. Soc. 2015, 137 (14), 4701-4708.

(36) Weng, L.-C.; Bell, A. T.; Weber, A. Z. A Systematic Analysis of Cu-Based Membrane-Electrode Assemblies for CO 2 Reduction through Multiphysics Simulation. Energy Environ. Sci. 2020, 13 
(10), 3592-3606.

(37) van Straelen, J.; Geuzebroek, F. The Thermodynamic Minimum Regeneration Energy Required for Post-Combustion CO2 Capture. Energy Procedia 2011, 4, 1500-1507.

(38) Wang, C.; Jiang, K.; Jones, T. W.; Yang, S.; Yu, H.; Feron, P.; Li, K. Electrowinning-Coupled CO2 Capture with Energy-Efficient Absorbent Regeneration: Towards Practical Application. Chem. Eng. J. 2021, 131981.

(39) Keith, D. W.; Holmes, G.; St. Angelo, D.; Heidel, K. A Process for Capturing CO2 from the Atmosphere. Joule 2018, 2 (8), 1573-1594.

(40) Ripatti, D. S.; Veltman, T. R.; Kanan, M. W. Carbon Monoxide Gas Diffusion Electrolysis That Produces Concentrated C2 Products with High Single-Pass Conversion. Joule. 2019, pp 240-256.

(41) Bhargava, S. S.; Proietto, F.; Azmoodeh, D.; Cofell, E. R.; Henckel, D. A.; Verma, S.; Brooks, C. J.; Gewirth, A. A.; Kenis, P. System Design Rules for Intensifying the Electrochemical Reduction of CO2 to CO on Ag Nanoparticles. ChemElectroChem 2020.

(42) Jeng, E.; Jiao, F. Investigation of CO2 Single-Pass Conversion in a Flow Electrolyzer. React. Chem. Eng. 2020, 5 (9), 1768-1775.

(43) Rabinowitz, J. A.; Kanan, M. W. The Future of Low-Temperature Carbon Dioxide Electrolysis Depends on Solving One Basic Problem. Nat. Commun. 2020, 11 (1), 5231.

(44) Welch, A. J.; Dunn, E.; DuChene, J. S.; Atwater, H. A. Bicarbonate or Carbonate Processes for Coupling Carbon Dioxide Capture and Electrochemical Conversion. ACS Energy Lett. 2020, 5 (3), 940-945.

(45) Danckwerts, P. V.; Lannus, A. Gas-Liquid Reactions. Journal of The Electrochemical Society. 1970, p 369C.

(46) Fukunaka, Y.; Jiang, M.-F.; Yamamoto, T.; Asaki, Z.; Kondo, Y. Nonuniformity of NaOH Concentration and Effective Bubble Diameter in $\mathrm{CO} 2$ Injection into Aqueous $\mathrm{NaOH}$ Solution. Metallurgical Transactions B 1989, 20 (1), 5-12. 